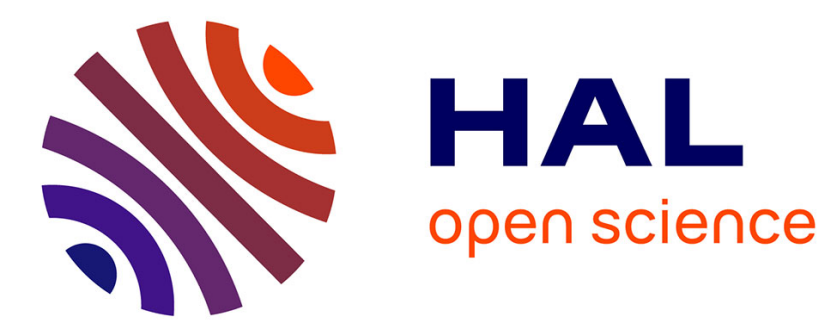

\title{
Nucleolus: A Central Hub for Nuclear Functions
}

Olga V Iarovaia, Elizaveta P Minina, Eugene V Sheval, Daria Onichtchouk, Svetlana Dokudovskaya, Sergey V Razin, Yegor Vassetzky

\section{To cite this version:}

Olga V Iarovaia, Elizaveta P Minina, Eugene V Sheval, Daria Onichtchouk, Svetlana Dokudovskaya, et al. Nucleolus: A Central Hub for Nuclear Functions. Trends in Cell Biology, 2019, 29 (8), pp.647-659. 10.1016/j.tcb.2019.04.003 . hal-02322927

\section{HAL Id: hal-02322927 https://hal.science/hal-02322927}

Submitted on 18 Nov 2020

HAL is a multi-disciplinary open access archive for the deposit and dissemination of scientific research documents, whether they are published or not. The documents may come from teaching and research institutions in France or abroad, or from public or private research centers.
L'archive ouverte pluridisciplinaire HAL, est destinée au dépôt et à la diffusion de documents scientifiques de niveau recherche, publiés ou non, émanant des établissements d'enseignement et de recherche français ou étrangers, des laboratoires publics ou privés. 
archives-ouvertes

\title{
Nucleolus: A Central Hub for Nuclear Functions
}

\author{
Olga Iarovaia, Elizaveta Minina, Eugene Sheval, Daria Onichtchouk, Svetlana \\ Dokudovskaya, Sergey Razin, Yegor Vassetzky
}

\section{To cite this version:}

Olga Iarovaia, Elizaveta Minina, Eugene Sheval, Daria Onichtchouk, Svetlana Dokudovskaya, et al.. Nucleolus: A Central Hub for Nuclear Functions. Trends in Cell Biology, Elsevier, 2019, 29 (8), pp.647-659. 10.1016/j.tcb.2019.04.003 . hal-02322927

\section{HAL Id: hal-02322927 \\ https://hal.archives-ouvertes.fr/hal-02322927}

Submitted on 18 Nov 2020

HAL is a multi-disciplinary open access archive for the deposit and dissemination of scientific research documents, whether they are published or not. The documents may come from teaching and research institutions in France or abroad, or from public or private research centers.
L'archive ouverte pluridisciplinaire HAL, est destinée au dépôt et à la diffusion de documents scientifiques de niveau recherche, publiés ou non, émanant des établissements d'enseignement et de recherche français ou étrangers, des laboratoires publics ou privés. 


\section{Trends in Cell Biology \\ Nucleolus: a central hub for nuclear functions \\ --Manuscript Draft--}

\begin{tabular}{|c|c|}
\hline Manuscript Number: & TCB-D-18-00157R1 \\
\hline Keywords: & $\begin{array}{l}\text { nucleolus; nuclear compartmentalization; protein shuttling; 3D genome organization; } \\
\text { DNA repair and recombination; transcription }\end{array}$ \\
\hline Corresponding Author: & $\begin{array}{l}\text { Yegor Vassetzky, Ph.D., D.Sc. } \\
\text { CNRS } \\
\text { Villejuif, IdF FRANCE }\end{array}$ \\
\hline First Author: & Olga V. Iarovaia \\
\hline \multirow[t]{5}{*}{ Order of Authors: } & Olga V. Iarovaia \\
\hline & Elizaveta P. Minina \\
\hline & Eugene V. Sheval \\
\hline & Sergey V. Razin \\
\hline & Yegor Vassetzky, Ph.D., D.Sc. \\
\hline Abstract: & $\begin{array}{l}\text { The nucleus contains distinct nuclear bodies (NBs); nucleolus is the largest and the } \\
\text { most studied NB, but its role in the functioning of the nucleus is far from being fully } \\
\text { understood. The nucleolus is not surrounded by a membrane, yet it contains DNA, } \\
\text { RNA and a set of proteins that can either be retained in the nucleolus or rapidly shuttle } \\
\text { between the nucleoplasm, the nucleolus and the cytoplasm in response to various } \\
\text { stimuli. The emerging evidence points to the central function of the nucleolus in } \\
\text { organizing many nuclear functions besides RNA polymerase I transcription and } \\
\text { ribosome biogenesis. Here we discuss the functions of the nucleolus related to the } \\
\text { shuttling of proteins and nucleic acids between nucleolus and nucleoplasm. The } \\
\text { functional processes affected by shuttling of nucleolar components include 3D } \\
\text { organization of the genome, stress response, DNA repair and recombination, } \\
\text { transcription regulation, telomere maintenance and other essential cellular functions. }\end{array}$ \\
\hline
\end{tabular}




\section{Highlights}

- Nucleolus is a PolI transcription factory and a place of ribosome assembly, but is also performs many other functions that are commonly referred to as non-canonical functions of nucleolus

- Nucleolus organizes the adjacent chromatin into a large-scale repressive hub underlying the spatial segregation of active and repressive chromatin compartments.

- The interphase chromosomes are attached to the nucleolus via nucleolus-associated domains (NADs).

- Protein shuttling between the nucleolus and the nucleoplasm regulates a multitude of nuclear processes including DNA repair, recombination, transcription and telomere maintenance.

- Sequestration of proteins within nucleolus allows decrease sharply their concentration within other cellular compartments.

- Perinucleolar regions contain a recombination compartment; they also participate in allelic exclusion and $\mathrm{X}$ chromosome silencing. 


\section{Nucleolus: a central hub for nuclear functions}

Olga V. Iarovaia ${ }^{1,2, *}$, Elizaveta P. Minina ${ }^{3, *}$, Eugene V. Sheval ${ }^{2,4,5,}$, Daria Onichtchouk ${ }^{6}$, Svetlana Dokudovskaya $^{2,8}$, Sergey V. Razin ${ }^{1,2,5}$ and Yegor S. Vassetzky ${ }^{2,7,8,9}$

${ }^{1}$ Institute of Gene Biology of the Russian Academy of Sciences, 119334 Moscow, Russia ${ }^{2}$ LIA 1066 LFR2O French-Russian Joint Cancer Research Laboratory, 94805 Villejuif, France

${ }^{3}$ Faculty of Bioengineering and Bioinformatics, Lomonosov Moscow State University, 119991 Moscow, Russia

${ }^{4}$ Belozersky Institute of Physico-Chemical Biology, Lomonosov Moscow State University, 119991 Moscow, Russia

${ }^{5}$ Faculty of Biology, Lomonosov Moscow State University, 119991 Moscow, Russia

${ }^{6}$ Developmental Biology Unit, Department of Biology I, University of Freiburg, Hauptstrasse 1, D-79104 Freiburg, Germany

${ }^{7}$ Koltzov Institute of Developmental Biology of the Russian Academy of Sciences, 119334 Moscow, Russia

${ }^{8}$ UMR8126, Université Paris-Sud, CNRS, Institut Gustave Roussy, 94805 Villejuif, France

${ }^{9}$ Corrsponding author

*equal contribution

\section{Keywords:}

Nuclear compartmentalization, nucleolus, 3D genome organization, DNA repair and recombination, transcription

\section{Word count: 3843}




\section{Summary}

The nucleolus is the largest and the most studied nuclear body, but its role in nuclear function is far from understood. Much work on the nucleolus has focused on its role in regulating RNA polymerase I transcription and ribosome biogenesis; however, emerging evidence points to the nucleolus as an organizing hub for many nuclear functions accomplished via shuttling of proteins and nucleic acids between the nucleolus and nucleoplasm. Here we discuss the cellular mechanisms affected by shuttling of nucleolar components that include 3D organization of the genome, stress response, DNA repair and recombination, transcription regulation, telomere maintenance and other essential cellular functions. 


\section{Glossary}

Allelic exclusion: a situation when one allele of a given gene is expressed while the other allele is transcriptionally inactive.

$\mathrm{Hi}$-C: a high-throughput method to study the three-dimensional architecture of genomes based on proximity ligation.

Nucleolus-associated domains (NADs): chromatin domains that dynamically interact with nucleoli.

Nucleolar localization signals (NoLS): a short protein sequence allowing to localize a protein inside the nucleolus. NoLS do not have a consensus sequence, but they are constantly enriched with positively charged amino acids. As a result, nucleolar accumulation via NoLS is dependent on the overall charge of the signal region.

Protein shuttling: most nuclear proteins are not tightly associated with nuclear bodies, but rather are continuously exchanged between these bodies and the surrounding nucleoplasm. This mobility allows these proteins to quickly relocalize between different nuclear domains, leading to unprecedented plasticity of the genome functioning.

Sequestration: mobile, continuously exchanging proteins can increase their concentration inside a nuclear body under some conditions. This process referred to as protein sequestration may be driven either by appearance of novel binding sites for the protein inside nucleoli, or disappearance of binding sited outside nucleoli, or posttranslational modifications of protein (or a combination thereof). Sequestration may also be due to a decrease of protein exchange due to 
tight association with a component(s) inside any subcellular structure (protein immobilization) or due to formation of protein aggregates.

Stress response: a reaction which dedicates energy and effort to acute adaptation to stress.

Topologically associating domain (TAD): a genomic region where DNA sequences physically interact with each other with a higher frequency as compared to the sequences outside the TAD. In mammals, TAD boundaries are enriched in $\mathrm{CTCF} / \mathrm{Cohesin}$ binding sites. Most interactions observed between gene enhancers and promoters occur within one TAD. TADs were shown to coincide with replication domains. 


\section{Introduction}

The main function of the nucleolus is the synthesis and processing of rRNA and ribosome assembly. Nucleoli contain clusters of ribosomal RNA genes (rDNA) and their transcripts (rRNA) (reviewed in [1]), as well as several hundred proteins participating in many nuclear processes inside and outside the nucleolus [2]. Recent data on nucleolar proteins and the analysis of genomic DNA loci associated with the nucleolus suggest that the function of the nucleolus is not limited to ribosome biogenesis, and that the nucleolus plays a role of a central hub regulating many nuclear and cellular processes. Movement of chromatin vs. the nucleolus may trigger activation and silencing of gene transcription $[3,4]$, mediate inactivation of chromatin domains [5], underlie allelic exclusion, and spatially organize gene recombination [6]. In a similar way, movement of proteins between the nucleolus and the nucleoplasm regulates DNA repair, RNA polymerase II transcription, telomere maintenance, stress response [7,8], and apoptosis [9]. Dynamic changes in localization of many proteins and chromatin regulated by the nucleolus appears to modulate a multitude of functions that were not previously associated with the nucleolus. These non-canonical functions of the nucleolus were discovered quite recently; therefore, the molecular mechanisms regulating these newly found nucleoli functions and the interactions of various components within the nucleolus remain unclear.

\section{Protein accumulation in the nucleolus}

The nucleolus is a membraneless organelle that forms through phase separation in the nucleus (Box 1). Protein accumulation inside nucleoli is a consequence of affinity interactions with core nucleolar components: rDNA, RNA and nucleolar proteins [10]. This accumulation is driven by short amino acid stretches referred to as nucleolar localisation sequences (NoLS) [11]. NoLS are substantially enriched with positively charged amino acids. Although there is no NoLS consensus sequence, approximately $50 \%$ of amino acids inside NoLS are lysines and arginines that generate a positive charge essential for nucleolar localization [12-15]. Thus, charge- 
dependent (electrostatic) interactions of amino acid residues with nucleolar components lead to their nucleolar accumulation. The nucleolus harbors a large number of negatively charged RNA molecules, potential targets for positively charged NoLS [14]. Of note, NoLS do not interact with DNA since its charge is neutralized by histones, bivalent ions and polyamines $[16,17]$. Low specificity of electrostatic accumulation via NoLSs allows a large number of proteins to be dynamically accumulated inside nucleoli. Nucleolar accumulation of proteins may also be due to their interaction with some nucleolar proteins including such as NCL (nucleolin or C23) which contains long acidic patches interacting with positively charged NoLS [18]. Nucleolar accumulation by NoLS is dynamic and can be affected by a variety of factors. For example, tumour suppressor ARF inhibits nucleolar import of TTF-I, a RNA polymerase I transcription termination factor, by binding to its NoLS, thus favouring TTF-I displacement from the nucleolus to the nucleoplasm [19] followed by the suppression of ribosomal RNA synthesis and cell proliferation arrest.

\section{Protein shuttling between the nucleolus and the nucleoplasm regulates nuclear processes}

Nucleolus is a highly dynamic structure involved in an active exchange of proteins between the nucleolus and the nucleoplasm (protein shuttling) [20,21]. In some cases, the appearance of strong retention centres outside of the nucleolus (e.g. recruitment of DNA repair machinery to DNA lesions) may lead to a decrease in the concentration of a protein within the nucleolus. Inversely, sequestration of various enzymes involved in stress response, DNA repair, cell cycle progression etc. within the nucleolus appears advantageous because it allows to keep the concentration of these proteins in the nucleoplasm relatively low under normal conditions and to increase it sharply upon stress. Excessive concentration of DNA repair enzymes and stress response factors in the nucleoplasm under normal conditions may result in a significant off-target activity. It seems thus logical to store these proteins within a dense phase-separated compartment until they become necessary to fulfil their specific functions [22]. 
The unique feature of the nucleolus is that it is both a storage place and a stress sensor. Some proteins are stored in the nucleolus irreversibly $[23,24]$. Other proteins perform major functions within the nucleolus and a moonlighting function in the nucleoplasm (Table 1). The third group of proteins have their main function in the nucleoplasm, but they are stored in the nucleolus until release (Table 2). Shuttling control is tightly connected with rDNA transcription and modulated by stresses, cell cycle progression, energy resources and various post-translational modifications. Below we discuss several examples demonstrating how the nucleolus integrates external signals and provides necessary responses to different stimuli.

DNA damage and repair. Cells are subjected to a multitude of DNA lesions resulting from oxidation, alkylation, exposure to UV light or irradiation. The response to these events may include DNA repair and cell-cycle arrest. The nucleolus plays an important role in DNA repair as it contains many DNA-binding proteins involved in DNA repair in the nucleoplasm and ribosome biogenesis in the nucleolus (Table 1, Figure 1). Switching between ribosome biogenesis and DNA repair functions is likely to occur through protein-protein interactions and posttranslational modifications regulating shuttling. For example, the apurinic/apyrimidinic endodeoxyribonuclease 1 (APE1; APEX1; REF-1) interacts with several nucleolar proteins via positively charged N-terminal lysine residues. In the nucleolus, APE1 interacts with NPM1 (also called B23, nucleophosmin, NO38 or numatrin), the 47S, 18S and 28S rRNAs [25] and deletes lesions from rRNA [26]. Deacetylation of N-terminal lysine residues upon DNA damage results in APE1 relocalization in the nucleoplasm where it is an essential component of base-excision repair machinery [26]. Another example concerns RecQ-like helicases WRN (Werner syndrome) and BLM (Bloom syndrome) implicated in double strand break (DSB) and base lesion repair in the nucleoplasm [27-29]. Phosphorylation [8], acetylation [30] and ubiquitination [31] of WRN and BLM regulates their shuttling between the nucleolus and nucleoplasm. WRN possesses a 
NoLS in its C-terminus and is normally located in the nucleolus where it interacts with RNA Pol I; the absence of WRN in the nucleolus reduces $18 \mathrm{~S}$ and $28 \mathrm{~S}$ rRNA levels [32]. When DNA repair is activated, WRN is dephosphorylated and moves from the nucleolus to the nucleoplasm [8]. This process is also modulated by acetylation [30]. In the nucleolus, BLM facilitates prerRNA synthesis by directly binding rDNA and interacting with RNA Pol I and DNA topoisomerase I [33-35]. BLM ubiquitination promotes its recruitment to DNA lesions while the absence of the RNF8 ubiquitin ligase results in its nucleolar sequestration [31].

Some proteins move into the nucleolus upon DNA damage: for example, a nucleoplasmic DNA damage response factor NBS1 can transiently accumulate in the nucleolus to inhibit rDNA transcription. Nucleolar localization of NBS1 depends on its interaction with the nucleolar protein Treacle (TCOF1). The Treacle-NBS1 complex acts as an adaptor for ATM kinase, which phosphorylates nucleolar proteins that regulate rDNA transcription in response to DNA damage. Activation of ATM kinase in the nucleus leads to translocation of the Treacle-NBS1 complex into the nucleolus and thus to silencing of rRNA transcription [36].

Similarly to many classical DNA repair enzymes located in the nucleolus, major nucleolar proteins NCL and NPM1 are rapidly exchanged between the nucleolus and the nucleoplasm so they can be readily available for DNA repair when necessary (Table 2, Figure 1) [7,37]. In particular, NCL translocates into the nucleoplasm and forms foci at sites of DSB repair where NCL is implicated in chromatin remodelling as a histone chaperone [38-41]. Relocalization of NPM1 from the nucleolus to the nucleoplasm is induced by DNA damaging agents such as ionizing radiation, cisplatin or etoposide treatment [42]. The relocalization of NPM1 to DSB repair foci is regulated by its phosphorylation [43]. In summary, DNA damage triggers an intense protein shuttling between the nucleolus and the nucleoplasm. Release of DNA repair 
factors stored in the nucleolus as well as bona fide nucleolar proteins into the nucleoplasm stimulates DNA repair.

Telomere maintenance. Telomerase is a ribonucleoprotein complex associated with the telomere repeats which protects the ends of the chromosomes from degradation. Telomerase contains the telomerase reverse transcriptase (TERT), telomerase RNA, and several additional proteins. Telomerase is assembled in the nucleolus by several proteins including dyskerin that later becomes a part of telomerase in the nucleoplasm [44]. Dyskerin also participates in pseudouridylation of specific residues in newly synthesized ribosomal RNAs and snRNAs [45]. Telomerase may be temporarily retained there under certain conditions through its interaction with NCL [46]. Retention of telomerase within the nucleolus is favorable in case of DNA damage as loosening of telomere structure should be necessary for DSB repair at telomeres [47]. Remarkably, TERT contains three NoLS [48-50]. TERT in the nucleolus stimulates RNA PolI transcription and binds rDNA during oncogenic and regenerative hyperproliferation, probably via activation of the transcription initiation complex formation [51] (Figure 1). The telomeric repeatbinding factor TRF2 also interacts with telomeres and protects them. TRF2 can be sequestered in the nucleolus by nucleolar protein NOLC1 [52], thereby affecting its function at telomeres [53]. NOLC1 overexpression and consequent relocalization of TRF2 to the nucleoli arrests cells in $\mathrm{G}_{0^{-}}$ $\mathrm{G}_{1}$ phase and prevents proliferation. In the nucleolus,TRF2 binds rDNA and promotes rRNA transcription [54].

Nucleolus and stress response. Although most nucleolar proteins are highly dynamic and shuttle between the nucleolus and the nucleoplasm $[37,55,56]$, these proteins can be retained in the nucleolus during transcriptional, acidic, or heat stress. Disruption of protein traffic through the nucleolus may lead to formation of intranucleolar protein complexes. One example is a cyclindependent kinase inhibitor p21cip (or p21), present both in the nucleus and the cytoplasm. In the 
cytoplasm, p21cip has oncogenic properties, while nuclear p21cip is a tumour suppressor. p21cip transits through the nucleolus on its way from the nucleus to the cytoplasm. DNA damage inhibits this transit and induces formation of p21cip-containing intranucleolar bodies (INoBs) [57]. These structures also contain SUMO-1 and UBC9, the E2 SUMO-conjugating enzyme, several DNA damage checkpoint proteins and cell cycle regulators Cdk2, Cyclin E, PCNA, p53 and MDM2 [58]. SUMO-1 and p21cip control the transit of proteins through the nucleolus, but when nucleolar export is disrupted by DNA damage, these proteins act as scaffolds that mediate the formation of the multiprotein complex in the nucleolus [58]. The MDM2-p53 pathway which coordinates cellular response to stress is also regulated by shuttling of the nucleolar proteins. In response to stress, several nucleolar proteins, including NCL [59], NPM [60], and nucleostemin [61], are released into the nucleoplasm, where they bind to and inhibit MDM2 resulting in p53 activation and stabilization (Figure 2).

Mammalian target of rapamycin (mTOR) pathway is another major cellular system that senses various types of stress and integrates intra- and extra-cellular cues for cell survival and degradation pathways [62]. One of the main functions of mTORC1 is activation of anabolic processes, including ribosome biogenesis and translation. Although mTOR complex 1 (mTORC1) is predominantly cytosolic and localizes around the lysosomal membrane, several members of mTORC1, including mTOR itself, can also locate to the nucleus and the nucleolus [63-69]. Nuclear mTOR protein can bind to thousands of sites in the genome $[66,67]$ and interact with rDNA chromatin either directly [63-65] or via modulation of other rDNA-interacting factors $[70,71]$. Treatment with mTORC1 inhibitor rapamycin prevents mTOR localization to the nucleolus and interferes with the processing of ribosomal rRNAs [68]. One of the recent examples of the nucleolar activity of mTORC1 is related to the function of inhibitor of growth $1 \mathrm{~b}$ protein (ING1b), which associates with rDNA repeats and is required for the efficient recruitment of chromatin regulator HDAC1 to the nucleoli [69]. ING1 reduces mTOR 
localization to the nucleolus and promotes recruitment of HDAC1 to the nucleolar remodelling complex (NoRC) complex and to major Pol I transcription factor UBF1. Inversely, knockdown of ING1 results in the accumulation of mTOR in nucleolus and it association with UBF1.

Sequestration of proteins in the nucleus. Although most of the shuttling between the nucleolus and the nucleoplasm is reversible, recent studies indicate that the nucleolus can sequester and store various nuclear and cytoplasmic proteins including misfolded protein aggregates. These aggregates form proteinaceous particles that can promote proteotoxic stress and eventually cell death if they are not cleared by the ubiquitin-proteasome system. Protein aggregates may also form directly in the nucleoli when proteasome function is inhibited. [72]. These inclusions form so-called 'aggresomes' [23] or 'detention centers' [24] within or in a close contact with the nucleoli (Figure 2); they are rich in protein and RNA [73]. Aggresome formation correlates with cell survival [74].

Various stresses lead not only to formation to misfolded proteins, but also to the expression of specific lncRNAs from the intergenic spacer separating individual rDNA transcription units (IGS lncRNAs) [75]. IGS lncRNA transcription correlates with the formation of nucleolar detention centers [24] retaining DNA (cytosine-5)-methyltransferase 1 (DNMT1), the $\delta$ catalytic subunit of DNA polymerase (POLD1), Hsp70, RNF8, MDM2, APC2 [75], RPA16, RPA40, PES1, NOP52, RRP1B, NOM1, NOL1, SENP3, and von Hippel-Lindau (VHL) protein [24]. VHL protein degrades the hypoxia-inducible factor (HIF) in the presence of oxygen; sequestration of VHL enables HIF to evade destruction and activate its target genes [76]. Immobilization of these proteins inside the nucleolus is driven by specific nucleolar detention signals (NoDS) [75]. Importantly, key nucleolar proteins FBL, NPM1, and NOPP140 that do not contain these signals remain mobile and evade retention, highlighting the specificity of this nucleolar sequestration [24]. 
Dynamic association of chromatin with the nucleolus controls 3D genome organization.

Nucleolus and 3D genome organisation Nucleus may contain one or several nucleoli that occupy up to $25 \%$ of its volume. The nucleolus is largely filled with transcribed rDNA and assembling ribosomes. In each cell, only a fraction of rRNA genes is transcriptionally active and localise within nucleoli. Inactive rDNA repeats are located at the periphery of the nucleolus contributing to the creation of a perinucleolar inactive chromatin compartment $[5,77,78]$. The presence of heterochromatin at the nucleolar periphery is directly related to the positioning of silenced ribosomal genes in this area [79]. Silencing of rDNA repeats is mediated by NoRC that recruits histone-modifying and DNA methylating enzymes [80,81]. The NoRC recruited to the perinucleolar region may also introduce heterochromatic marks into other chromatin regions in the vicinity of the nucleolus. Interestingly, centromeric heterochromatin is frequently located close to nucleolus, and depletion of TIP5, a subunit of NoRC compromises both rDNA silencing and assembly of centromeric heterochromatin [82].

Genomic segments located within perinucleolar compartment are commonly referred to as nucleolus-associated chromatin domains (NADs) [83,84]. NADs contain sequences located in the short arms of acrocentric chromosomes, centromeric and pericentromeric chromatin of most chromosomes and subtelomeric regions of some chromosomes (Figure 3). Besides repetitive sequences, NADs contain more than 1000 genes including those encoding for the T-cell receptors, olfactory receptors and two families of immunoglobulin genes. Many NAD-associated genes have similar features: they are tissue-specific and form large gene clusters [85]. NADs substantially overlap with lamina-associated domains (LADs) [86]. Only a portion of LADs identified in population studies is located close to nuclear lamina. After mitosis, LADs are 
stochastically reshuffled, and LADs redistributed to the nuclear interior are frequently localised within the perinucleolar region [87].

What is the functional significance of NADs and how the nucleolus can regulate their functions? NADs are globally enriched in heterochromatin marks, including H3K27me3, H3K9me3, and H4K20me3. Gene targeting to the nucleolus and the perinucleolar region is globally correlated with reduced gene expression [88]. Localization of NADs in the peripheral region of the nucleolus may thus contribute to gene silencing [5]. Regulation of gene expression may involve changes in gene positioning or the pattern of their contacts with the nucleolus. Indeed, some processes are accompanied by relocalization of genomic loci vs. the nucleolus. For example, centromeric and pericentromeric repeats are dissociated from the nucleolus in aging cells [89]. Association with the nucleolus globally correlates with the inactive transcriptional state of RNA polymerase II-transcribed genes. Some exceptions exist: translocations of the CCNDI and MYC genes to the acrocentric chromosome 14 into the locus of the immunoglobulin heavy chain $(I G H)$ genes lead to their relocalization towards the perinucleolar region and activation by NCL [4]. Association of the $I G H$ genes with the nucleolus may also be necessary for recombination. Thus, B-cell maturation is accompanied by relocalization of the $I G H$ locus in the prenucleolar region to a specific "recombination compartment" containing an activation-induced cytidine deaminase (AID). Somatic hypermutation and class-switch recombination of immunoglobulin genes take place in these "recombination compartments" [6]. Localization of genes other than $I G H$ within this compartment may significantly increase the probability of oncogenic translocations in B-cells [90]. Association of one allele of a monoallelically expressed gene with the nucleolus may participate in stochastic or imprinted allelic exclusion which could be the case for $T C R, I G H$ and olfactory receptor genes [91,92]. 
In the interphase nucleus, each chromosome forms a distinct chromosomal territory that is likely linked to both the nuclear lamina and the nucleolus because every chromosome contains both LADs and NADs. Being attached to the nucleolus, the nuclear lamina and to each other $[93,94]$, chromosomal territories constitute a unified chromatin compartment that is mechanically stretched [95] and can sense mechanical stress [96]. In this scenario, phase-separated nuclear compartments, the largest of which is the nucleolus, act as global chromatin organizers $[94,96]$. In particular, tethering of chromatin to the nucleolus and nuclear speckles is likely to account for the spatial segregation of repressed and active chromatin compartments [97]. These compartments likely corresponding to heterochromatin and euchromatin were identified by Hi-C [97]. Besides repressed and active chromatin compartments Hi-C and other recently developed experimental procedures allowed to identify self-interacting topologically associating domains (TADs) and contacts between chromosomes [94,97-99]. Interaction between the nucleolus and extra-nucleolar chromatin may stabilize weak interchromosomal contacts and serve as a centrefold for the arrangement of chromosomal territories inside the nucleus [100]. The association of specific genomic loci with the nucleolus may occur through their interaction with rDNA. Recent HiC experiments demonstrated that $5 \mathrm{~S}$ and $45 \mathrm{~S}$ gene arrays formed multiple contacts with genomic regions and genes on all chromosomes [101].

Association of chromatin with the nucleolus is mediated both by proteins and RNA. Nucleolar proteins Ki-67, NCL and NPM1 mediate the association of chromatin with the nucleolus. These proteins interact with CAF1, a chromatin assembly factor [89]. Depletion of the p150 CAF1 subunit leads to a decreased association of certain genomic loci, including the $5 \mathrm{~S}$ rDNA, alpha satellite DNA, and the D4Z4 macrosatellite, with nucleoli in human cells [102]. Depletion of NLP, a Drosophila homolog of NPM1, resulted in de-clustering of centromeres and a decrease in centromere association with the nucleolus [103]. Normal fibroblasts and cancer cells depleted of NPM1 displayed deformed nucleoli and a striking rearrangement of perinucleolar 
heterochromatin [104]. NPM1 also associates with HP1 $\gamma$, core linker histones and a centromerespecific histone variant CENP-A [105]; NPM1 is required for efficient tethering of HP1 $\gamma$ enriched chromatin to the nucleolus. Thus, interaction with chromatin and, in particular, heterochromatin proteins may be a major driver of chromatin anchoring to the nucleolus. CTCF, a structural protein that regulates 3D genome folding into TADs that often include co-regulated and co-transcribed genes (reviewed in $[106,107]$ ), may also anchor/target specific loci to the perinucleolar space. CTCF interacts with NPM1 to tether insulators to the nucleolar periphery [108]. In Drosophila, CTCF interacts with NLP and the nucleolar protein Modulo to position centromeres in the perinucleolar region [103].

Non-coding RNAs participate in the chromatin tethering towards the nucleolar periphery as well. For example, Xist and Firre non-coding RNAs (ncRNA) participate in X inactivation. Xist is responsible for the association of the inactive $\mathrm{X}$ chromosome with the nucleolar periphery [109]. Xist loss after $\mathrm{X}$ inactivation leads to dissociation of $\mathrm{X}$ chromosome from the nucleolus. Interestingly, autosomes bearing translocations with the $\mathrm{X}$ chromosome also become preferentially associated with the nucleolus [110]. Firre is expressed from a perinucleolar locus located on the X-chromosome; this locus contains CTCF and cohesin binding sites [111]. Firre transcription from the inactive $\mathrm{X}$ chromosome cooperates with $\mathrm{CTCF}$ binding to ensure perinucleolar positioning. Knockdown of Firre or its interaction partner hnRNPU interferes with the perinucleolar targeting of the inactive X chromosome. An imprinted antisense Kcnqlot ncRNA is transcribed only from the paternal allele and insures the allelic exclusion by targeting the paternal locus to the perinucleolar space where this $1 \mathrm{Mbp}$ region containing ten proteincoding genes is silenced [112,113]. Thus, nucleolus plays an important role in the 3D organization of the genome. It participates in organization of chromosome compartments and territories as well as heterochromatin assembly. This process involves several nucleolar proteins and non-coding RNAs. 


\section{Concluding remarks}

The key role of nucleolus as a regulatory hub is directly related to its main function, production of ribosomes. This process consumes more than a half of cell energy resources and thus should be coordinated with the actual needs of the cell in the ribosomes. Accordingly, many regulatory circuits link the production of ribosomes to the cell cycle progression which, in turn, can be blocked by stress responses. It is thus not surprising that nucleolus acquired a role of regulatory hub connecting many functional processes. The fundamental link between ribosome biogenesis and cell cycle progression is accomplished through involvement of certain proteins in cell cycle control and stress response on the one hand, and the regulation of ribosomal gene transcription and ribosome assembly on the other hand. Many of these proteins are sequestered within phaseseparated nucleoli but may shuttle to nucleoplasm in response to various stimuli.

The principal role of nucleolus in the $3 \mathrm{D}$ organization of the genome consists in creation of a nucleation center for the assembly of heterochromatin. This nucleation is due to silenced rRNA genes. Silencing of a portion of rRNA genes is an ancient phenomenon occurring even in lower eukaryotes. In multicellular organisms, the mechanism that silenced rRNA genes could be extended to other genes that are not used in various types of differentiated cells. Further studies will help us to decrypt the amazing complexity of the nucleols (see Outstanding questions).

\section{Acknowledgements}

We thank Dr. S.A. Golyshev for drawing the figures and many colleagues in the field for stimulating discussions and apologize that we could not acknowledge all relevant work due to space constraints. This work was supported by grants from Plan Cancer (ENVIBURKITT), and ANRS to YV, by the Russian Foundation for Basic Research (16-54-16014) and Russian Science 
Foundation (19-14-00016) to SVR, and by the Russian Science Foundation (18-14-00195) to EVS. 


\section{Box 1}

\section{Membraneless nuclear compartments}

Eukaryotic cell nucleus contains a number of membraneless compartments such as nucleoli,

Cajal bodies, PML bodies, nuclear speckles etc. [114]. These compartments are dynamic associates of proteins and nucleic acids and are slightly denser than the bulk of the nucleoplasm. Each type of membraneless compartments is connected to certain functional processes that are not necessarily related to each other [115]. Accordingly, most of the compartments contain a number of various proteins including many moonlighting proteins [116]. The proteins participating in assembly of nuclear compartments frequently possess intrinsically disordered domains [116-118]. These proteins/domains may mediate weak-affinity and non-specific interactions with multiple target sites that trigger the liquid phase separation [119]. The phaseseparated droplets accumulate macromolecules that possess an affinity to the components of the droplet interior. Usually a so called platform nucleates the assembly of liquid droplet nuclear compartments. This may be either a protein (e.g. PML in case of PML-bodies [120]) or a noncoding RNA (e.g. NEAT1 RNA in paraspeckles [121] or rRNA in nucleoli [122]). The nucleolus differs from other membraneless compartments in two ways. First, the nucleolus consists of at least three distinct phase-separated layers: droplets within droplets [123]. Second, the availability of pre-rRNAs that constitutes a platform for nucleolus assembly directly depends on the ongoing rDNA transcription [124]. Suppression of rDNA transcription results in full or partial disruption of nucleoli and release into cytoplasm of a various proteins sequestered within nucleoli [124]. This is likely to be an important part of the cellular stress response mechanism [125]. 


\section{Figure Legends}

Figure 1. DNA repair and telomere maintenance are regulated by protein shuttling between the nucleolus and the nucleoplasm.

Clockwise: APE1 interacts with nucleolar proteins NPM1 via its positively charged lysine residues. When some of these lysine residues are acetylated, NPM1 no longer interacts with APE1 and APE1 accumulates in nucleoplasm at the DNA damage sites. Nucleolar mTOR activates PolI transcription. WRN possesses a NoLS in its C-terminus; nucleolar localization of WRN is dependent on RNA Pol I transcription. When DNA repair is activated, WRN is dephosphorylated and moves from nucleolus to nucleoplasm. BLM can directly bind rDNA and interact with RNA Pol I. BLM switching between DNA repair and ribosome biogenesis occurs through protein-protein interactions and posttranslational modifications. TRAIP encodes a nucleolar protein that migrates to UV-induced DNA lesions in the nucleoplasm; inhibition of RNA Pol I activity also leads to TRAIP diffusion into the nucleoplasm. The telomerase complex biogenesis occurs in the nucleolus; TERT is retained in nucleoli through its interaction with NCL. Nucleolar localization of TRF2 is promoted by the nucleolar protein NOLC1. TRF2 also binds rDNA and promotes rRNA transcription. NCL forms nucleoplasmic foci at sites of DSB repair where it is implicated in chromatin remodelling while the mail pool of NCL is located in the nucleolus. Ionizing radiation, cisplatin or etoposide treatment leads to NPM1 phosphorylation and its relocalization from the nucleolus to the DSB foci in the nucleoplasm.

Figure 2. Sequestration of nuclear and cytoplasmic proteins in the nucleolus.

Misfolded proteins aggregate and form proteinaceous particles that are transported into the nucleolus form so-called 'aggresomes' or 'detention centers'. p21Cip1 transits through the nucleolus on its way from the nucleus to the cytoplasm. DNA damage inhibits this transit and induces formation of p21Cip1-containing intranucleolar bodies (INoBs) containing SUMO-1, UBC9, Cdk2, Cyclin E, PCNA, p53 and MDM2. Transcriptional, acidic or heat stress leads to 
expression of lncRNAs from the rDNA intergenic spacer. These transcripts capture and immobilize inside nucleoli several important proteins, including VHL, DNMT1, tPOLD1, Hsp70, RNF8, MDM2, APC2, RPA16 and RPA40, PES1, NOP52, RRP1B, NOM1, NOL1, and SENP3. Key nucleolar proteins FBL, NPM1, and NOPP140 retain their mobility and evade immobilization, highlighting the specificity of this nucleolar sequestration.

Figure 3. Dynamic association of chromatin with the nucleolus regulates nuclear processes Clockwise: nucleoli-associated chromatin domains (NADs) represent hundreds of extended genomic loci comprising $4 \%$ of the human genome. NADs contain sequences located in the parms of acrocentric chromosomes, centromeric and pericentromeric chromatin of most chromosomes and subtelomeric regions of some chromosomes. Association with the nucleolus globally correlates with the inactive transcriptional state of RNA polymerase II-transcribed genes, with some exceptions. Association with the nucleolus may also participate in allelic exclusion. Somatic hypermutation and class-switch recombination occur in the specific "recombination compartment" located in the prenucleolar region and containing AID. Inactive X chromosome is associated with the nucleolar periphery; this association is due to Xist and Firre non-coding RNAs.

\section{References}

1 Hernandez-Verdun, D. et al. (2010) The nucleolus: structure/function relationship in RNA metabolism. Wiley Interdiscip. Rev. RNA 1, 415-431

2 Andersen, J.S. et al. (2005) Nucleolar proteome dynamics. Nature 433, 77-83

3 Padeken, J. and Heun, P. (2014) Nucleolus and nuclear periphery: Velcro for heterochromatin. Curr. Opin. Cell Biol. 28, 54-60

4 Allinne, J. et al. (2014) Perinucleolar relocalization and nucleolin as crucial events in the transcriptional activation of key genes in mantle cell lymphoma. Blood 123, 2044-53

5 Matheson, T.D. and Kaufman, P.D. (2016) Grabbing the genome by the NADs. 


\section{Chromosoma 125, 361-71}

6 Pichugin, A. et al. (2017) The IGH locus relocalizes to a "recombination compartment" in the perinucleolar region of differentiating B-lymphocytes. Oncotarget 8,

7 Scott, D.D. and Oeffinger, M. (2016) Nucleolin and nucleophosmin: nucleolar proteins with multiple functions in DNA repair. Biochem. Cell Biol. 94, 419-432

8 Ogawa, L.M. and Baserga, S.J. (2017) Crosstalk between the nucleolus and the DNA damage response. Mol. Biosyst. 13, 443-455

9 Boulon, S. et al. (2010) The nucleolus under stress. Mol. Cell 40, 216-27

10 Carmo-Fonseca, M. et al. (2000) To be or not to be in the nucleolus. Nat Cell Biol 2, E107-12

11 Emmott, E. and Hiscox, J.A. (2009) Nucleolar targeting: the hub of the matter. EMBO Rep. 10, 231-8

12 Musinova, Y.R. et al. (2011) Nucleolar localization/retention signal is responsible for transient accumulation of histone $\mathrm{H} 2 \mathrm{~B}$ in the nucleolus through electrostatic interactions. Biochim. Biophys. Acta - Mol. Cell Res. 1813, 27-38

13 Savada, R.P. and Bonham-Smith, P.C. (2013) Charge versus sequence for nuclear/nucleolar localization of plant ribosomal proteins. Plant Mol. Biol. 81, 477-93

14 Martin, R.M. et al. (2015) Principles of protein targeting to the nucleolus. Nucleus 6, 314 25

15 Musinova, Y.R. et al. (2015) A charge-dependent mechanism is responsible for the dynamic accumulation of proteins inside nucleoli. Biochim. Biophys. Acta - Mol. Cell Res. $1853,101-110$

16 Visvanathan, A. et al. (2013) Modulation of Higher Order Chromatin Conformation in Mammalian Cell Nuclei Can Be Mediated by Polyamines and Divalent Cations. PLoS One 8, e67689

17 Maeshima, K. et al. (2018) A Transient Rise in Free Mg 2+ Ions Released from ATP-Mg 
Hydrolysis Contributes to Mitotic Chromosome Condensation. Curr. Biol. 28, 444-451.e6

18 Sen Gupta, A. et al. (2018) Nucleolin modulates compartmentalization and dynamics of histone 2B-ECFP in the nucleolus. Nucleus DOI: 10.1080/19491034.2018.1471936

19 Lessard, F. et al. (2010) The ARF Tumor Suppressor Controls Ribosome Biogenesis by Regulating the RNA Polymerase I Transcription Factor TTF-I. Mol. Cell 38, 539-550

20 Misteli, T. (2001) Protein dynamics: implications for nuclear architecture and gene expression. Science 291, 843-7

21 Dundr, M. and Misteli, T. (2001) Functional architecture in the cell nucleus. Biochem. J. $356,297-310$

22 Handwerger, K.E. et al. (2005) Cajal Bodies, Nucleoli, and Speckles in the Xenopus Oocyte Nucleus Have a Low-Density, Sponge-like Structure. Mol. Biol. Cell 16, 202-211

23 Komarova, T. V et al. (2012) Rapid and massive green fluorescent protein production leads to formation of protein Y-bodies in plant cells. Biochemistry. (Mosc). 77, 603-8

24 Jacob, M.D. et al. (2013) Environmental cues induce a long noncoding RNA-dependent remodeling of the nucleolus. Mol. Biol. Cell 24, 2943-2953

25 Lirussi, L. et al. (2012) Nucleolar accumulation of APE1 depends on charged lysine residues that undergo acetylation upon genotoxic stress and modulate its BER activity in cells. Mol. Biol. Cell 23, 4079-96

26 Vascotto, C. et al. (2009) APE1/Ref-1 Interacts with NPM1 within Nucleoli and Plays a Role in the rRNA Quality Control Process. Mol. Cell. Biol. 29, 1834-1854

27 Chen, L. et al. (2003) WRN, the protein deficient in Werner syndrome, plays a critical structural role in optimizing DNA repair. Aging Cell 2, 191-199

28 Grabarz, A. et al. (2013) A role for BLM in double-strand break repair pathway choice: prevention of CtIP/Mre11-mediated alternative nonhomologous end-joining. Cell Rep. 5, $21-8$

29 Brosh, R.M. (2013) DNA helicases involved in DNA repair and their roles in cancer. Nat. 
Rev. Cancer 13, 542-558

30 Blander, G. et al. (2002) DNA damage-induced translocation of the Werner helicase is regulated by acetylation. J. Biol. Chem. 277, 50934-40

31 Tikoo, S. et al. (2013) Ubiquitin-dependent recruitment of the Bloom Syndrome helicase upon replication stress is required to suppress homologous recombination. EMBO J. 32, $1778-1792$

32 Shiratori, M. et al. (2002) WRN helicase accelerates the transcription of ribosomal RNA as a component of an RNA polymerase I-associated complex. Oncogene 21, 2447-54

33 Tangeman, L. et al. (2016) Regulation of BLM Nucleolar Localization. Genes (Basel). 7, 69

34 Grierson, P.M. et al. (2012) BLM helicase facilitates RNA polymerase I-mediated ribosomal RNA transcription. Hum. Mol. Genet. 21, 1172-83

35 Grierson, P.M. et al. (2013) Collaborating functions of BLM and DNA topoisomerase I in regulating human rDNA transcription. Mutat. Res. 743-744, 89-96

36 Larsen, D.H. et al. (2014) The NBS1-Treacle complex controls ribosomal RNA transcription in response to DNA damage. Nat. Cell Biol. 16, 792-803

37 Chen, D. and Huang, S. (2001) Nucleolar components involved in ribosome biogenesis cycle between the nucleolus and nucleoplasm in interphase cells. J. Cell Biol. 153, 169-76

38 Indig, F.E. et al. (2012) Nucleolin inhibits G4 oligonucleotide unwinding by Werner helicase. PLoS One 7, e35229

39 Kobayashi, J. et al. (2012) Nucleolin participates in DNA double-strand break-induced damage response through MDC1-dependent pathway. PLoS One 7, e49245

40 Goldstein, M. et al. (2013) Nucleolin mediates nucleosome disruption critical for DNA double-strand break repair. Proc. Natl. Acad. Sci. 110, 16874-16879

41 Angelov, D. et al. (2006) Nucleolin is a histone chaperone with FACT-like activity and assists remodeling of nucleosomes. EMBO J. 25, 1669-1679 
42 Poletto, M. et al. (2014) Nucleophosmin modulates stability, activity, and nucleolar accumulation of base excision repair proteins. Mol. Biol. Cell 25, 1641-52

43 Koike, A. et al. (2010) Recruitment of phosphorylated NPM1 to sites of DNA damage through RNF8-dependent ubiquitin conjugates. Cancer Res. 70, 6746-56

44 Fu, D. and Collins, K. (2007) Purification of Human Telomerase Complexes Identifies Factors Involved in Telomerase Biogenesis and Telomere Length Regulation. Mol. Cell $28,773-785$

45 Angrisani, A. et al. (2014) Human dyskerin: beyond telomeres. Biol. Chem. 395, 593-610

46 Lee, J.H. et al. (2014) Catalytically active telomerase holoenzyme is assembled in the dense fibrillar component of the nucleolus during S phase. Histochem. Cell Biol. 141, $137-152$

47 Wong, J.M.Y. et al. (2002) Subnuclear shuttling of human telomerase induced by transformation and DNA damage. Nat. Cell Biol. 4, 731-6

48 Yang, Y. et al. (2002) Nucleolar localization of hTERT protein is associated with telomerase function. Exp. Cell Res. 277, 201-9

49 Etheridge, K.T. et al. (2002) The Nucleolar Localization Domain of the Catalytic Subunit of Human Telomerase. J. Biol. Chem. 277, 24764-24770

50 Lin, J. et al. (2008) Nucleolar localization of TERT is unrelated to telomerase function in human cells. J. Cell Sci. 121, 2169-2176

51 Gonzalez, O.G. et al. (2014) Telomerase stimulates ribosomal DNA transcription under hyperproliferative conditions. Nat. Commun. 5, 4599

52 Yuan, F. et al. (2017) Nucleolar and coiled-body phosphoprotein 1 (NOLC1) regulates the nucleolar retention of TRF2. Cell death Discov. 3, 17043

53 Zhang, S. et al. (2004) Nucleolar localization of the human telomeric repeat binding factor 2 (TRF2). J. Cell Sci. 117, 3935-3945

54 Yuan, F. et al. (2018) Nucleolar TRF2 attenuated nucleolus stress-induced HCC cell-cycle 
arrest by altering rRNA synthesis. Cell Death Dis. 9, 518

55 Phair, R.D. and Misteli, T. (2000) High mobility of proteins in the mammalian cell nucleus. Nature 404, 604-9

56 Dundr, M. et al. (2000) The dynamics of postmitotic reassembly of the nucleolus. J. Cell Biol. 150, 433-46

57 Abella, N. et al. (2010) Nucleolar Disruption Ensures Nuclear Accumulation of p21 upon DNA Damage. Traffic 11, 743-755

58 Brun, S. et al. (2017) SUMO regulates p21Cip1 intracellular distribution and with p21Cip1 facilitates multiprotein complex formation in the nucleolus upon DNA damage. PLoS One 12, e0178925

59 Saxena, A. et al. (2006) Nucleolin inhibits Hdm2 by multiple pathways leading to p53 stabilization. Oncogene 25, 7274-7288

60 Kurki, S. et al. (2004) Nucleolar protein NPM interacts with HDM2 and protects tumor suppressor protein p53 from HDM2-mediated degradation. Cancer Cell 5, 465-75

61 Meng, L. et al. (2008) Nucleoplasmic mobilization of nucleostemin stabilizes MDM2 and promotes G2-M progression and cell survival. J. Cell Sci. 121, 4037-4046

62 Ma, Y. et al. (2018) mTORC1 pathway in DNA damage response. Biochim. Biophys. Acta - Mol. Cell Res. 1865, 1293-1311

63 Li, H. et al. (2006) Nutrient regulates Tor1 nuclear localization and association with rDNA promoter. Nature 442, 1058-1061

64 Tsang, C.K. et al. (2003) Chromatin-mediated regulation of nucleolar structure and RNA Pol I localization by TOR. EMBO J. 22, 6045-6056

65 Tsang, C.K. et al. (2010) mTOR binds to the promoters of RNA polymerase I- and IIItranscribed genes. Cell Cycle 9, 953-7

66 Audet-Walsh, É. et al. (2017) Nuclear mTOR acts as a transcriptional integrator of the androgen signaling pathway in prostate cancer. Genes Dev. 31, 1228-1242 
67 Chaveroux, C. et al. (2013) Molecular and Genetic Crosstalks between mTOR and ERR $\alpha$ Are Key Determinants of Rapamycin-Induced Nonalcoholic Fatty Liver. Cell Metab. 17, $586-598$

68 Iadevaia, V. et al. (2012) mTOR signaling regulates the processing of pre-rRNA in human cells. Nucleic Acids Res. 40, 2527-2539

69 Rajarajacholan, U.K. et al. (2017) ING1 regulates rRNA levels by altering nucleolar chromatin structure and mTOR localization. Nucleic Acids Res. 45, 1776-1792

70 Grove, A. (2018) Control of RNA polymerase II-transcribed genes by direct binding of TOR kinase. Curr. Genet. 64, 131-135

71 Panday, A. et al. (2017) DNA damage regulates direct association of TOR kinase with the RNA polymerase II-transcribed HMOI gene. Mol. Biol. Cell 28, 2449-2459

72 Latonen, L. et al. (2011) Proteasome inhibitors induce nucleolar aggregation of proteasome target proteins and polyadenylated RNA by altering ubiquitin availability. Oncogene 30, 790-805

73 Goggin, K. et al. (2008) Prion protein aggresomes are poly(A)+ ribonucleoprotein complexes that induce a PKR-mediated deficient cell stress response. Biochim. Biophys. Acta - Mol. Cell Res. 1783, 479-491

74 Kawaguchi, Y. et al. (2003) The deacetylase HDAC6 regulates aggresome formation and cell viability in response to misfolded protein stress. Cell 115, 727-38

75 Audas, T.E. et al. (2012) Immobilization of proteins in the nucleolus by ribosomal intergenic spacer noncoding RNA. Mol. Cell 45, 147-57

76 Mekhail, K. et al. (2004) HIF activation by pH-dependent nucleolar sequestration of VHL. Nat. Cell Biol. 6, 642-647

77 Pontvianne, F. et al. (2013) Subnuclear partitioning of rRNA genes between the nucleolus and nucleoplasm reflects alternative epiallelic states. Genes Dev. 27, 1545-1550

78 Jakociunas, T. et al. (2013) Subnuclear relocalization and silencing of a chromosomal 
region by an ectopic ribosomal DNA repeat. Proc. Natl. Acad. Sci. 110, E4465-E4473

79 Zhou, Y. et al. (2002) The chromatin remodeling complex NoRC targets HDAC1 to the ribosomal gene promoter and represses RNA polymerase I transcription. EMBO J. 21, $4632-40$

80 Santoro, R. and Grummt, I. (2005) Epigenetic mechanism of rRNA gene silencing: temporal order of NoRC-mediated histone modification, chromatin remodeling, and DNA methylation. Mol. Cell. Biol. 25, 2539-46

81 Santoro, R. et al. (2002) The nucleolar remodeling complex NoRC mediates heterochromatin formation and silencing of ribosomal gene transcription. Nat. Genet. 32, 393-396

82 Guetg, C. et al. (2010) The NoRC complex mediates the heterochromatin formation and stability of silent rRNA genes and centromeric repeats. EMBO J. 29, 2135-46

83 van Koningsbruggen, S. et al. (2010) High-Resolution Whole-Genome Sequencing Reveals That Specific Chromatin Domains from Most Human Chromosomes Associate with Nucleoli. Mol. Biol. Cell 21, 3735-3748

84 Németh, A. et al. (2010) Initial genomics of the human nucleolus. PLoS Genet. 6, e1000889

85 Padeken, J. and Heun, P. (2014) Nucleolus and nuclear periphery: velcro for heterochromatin. Curr. Opin. Cell Biol. 28, 54-60

86 Guelen, L. et al. (2008) Domain organization of human chromosomes revealed by mapping of nuclear lamina interactions. Nature 453, 948-951

87 Kind, J. et al. (2013) Single-cell dynamics of genome-nuclear lamina interactions. Cell $153,178-192$

88 Fedoriw, A.M. et al. (2012) Nucleolar Association and Transcriptional Inhibition through 5S rDNA in Mammals. PLoS Genet. 8, e1002468

89 Dillinger, S. et al. (2017) Nucleolus association of chromosomal domains is largely 
maintained in cellular senescence despite massive nuclear reorganisation. PLoS One 12, $\mathrm{e} 0178821$

90 Sklyar, I. et al. (2016) Distinct Patterns of Colocalization of the CCND1 and CMYC Genes With Their Potential Translocation Partner IGH at Successive Stages of B-Cell Differentiation. J. Cell. Biochem. 117, 1506-1510

91 Rada, C. and Ferguson-Smith, A.C. (2002) Epigenetics: monoallelic expression in the immune system. Curr. Biol. 12, R108-10

92 Monahan, K. and Lomvardas, S. (2015) Monoallelic expression of olfactory receptors. Annu. Rev. Cell Dev. Biol. 31, 721-40

93 Kalhor, R. et al. (2011) Genome architectures revealed by tethered chromosome conformation capture and population-based modeling. Nat. Biotechnol. 30, 90-8

94 Quinodoz, S.A. et al. (2018) Higher-Order Inter-chromosomal Hubs Shape 3D Genome Organization in the Nucleus. Cell 174, 744-757.e24

95 Ulianov, S. V et al. (2019) Nuclear lamina integrity is required for proper spatial organization of chromatin in Drosophila. Nat. Commun. 10, 1176

96 Shin, Y. et al. (2018) Liquid Nuclear Condensates Mechanically Sense and Restructure the Genome. Cell 175, 1481-1491.e13

97 Lieberman-Aiden, E. et al. (2009) Comprehensive mapping of long-range interactions reveals folding principles of the human genome. Science (80-. ). 326, 289-293

98 Rao, S.S.P. et al. (2014) A 3D map of the human genome at kilobase resolution reveals principles of chromatin looping. Cell 159, 1665-80

99 Beagrie, R.A. et al. (2017) Complex multi-enhancer contacts captured by genome architecture mapping. Nature 543, 519-524

100 Pontvianne, F. et al. (2016) Identification of Nucleolus-Associated Chromatin Domains Reveals a Role for the Nucleolus in 3D Organization of the A. thaliana Genome. Cell Rep. $16,1574-1587$ 
101 Yu, S. and Lemos, B. (2016) A Portrait of Ribosomal DNA Contacts with Hi-C Reveals 5S and 45S rDNA Anchoring Points in the Folded Human Genome. Genome Biol. Evol. 8, $3545-3558$

102 Smith, C.L. et al. (2014) A separable domain of the p150 subunit of human chromatin assembly factor-1 promotes protein and chromosome associations with nucleoli. Mol. Biol. Cell 25, 2866-81

103 Padeken, J. et al. (2013) The nucleoplasmin homolog NLP mediates centromere clustering and anchoring to the nucleolus. Mol. Cell 50, 236-49

104 Holmberg Olausson, K. et al. (2014) Loss of Nucleolar Histone Chaperone NPM1 Triggers Rearrangement of Heterochromatin and Synergizes with a Deficiency in DNA Methyltransferase DNMT3A to Drive Ribosomal DNA Transcription. J. Biol. Chem. 289, $34601-34619$

105 Foltz, D.R. et al. (2006) The human CENP-A centromeric nucleosome-associated complex. Nat. Cell Biol. 8, 458-69

106 Eagen, K.P. (2018) Principles of Chromosome Architecture Revealed by Hi-C. Trends Biochem. Sci. 43, 469-478

107 Razin, S. V and Ulianov, S. V (2017) Gene functioning and storage within a folded genome. Cell. Mol. Biol. Lett. 22, 18

108 Yusufzai, T.M. et al. (2004) CTCF Tethers an Insulator to Subnuclear Sites, Suggesting Shared Insulator Mechanisms across Species. Mol. Cell 13, 291-298

109 Zhang, L.-F. et al. (2007) Perinucleolar Targeting of the Inactive X during S Phase: Evidence for a Role in the Maintenance of Silencing. Cell 129, 693-706

110 Zhang, Y. et al. (2012) Spatial organization of the mouse genome and its role in recurrent chromosomal translocations. Cell 148, 908-21

111 Yang, F. et al. (2015) The lncRNA Firre anchors the inactive X chromosome to the nucleolus by binding CTCF and maintains H3K27me3 methylation. Genome Biol. 16, 52 
112 Mohammad, F. et al. (2008) Kcnq1ot1/Lit1 noncoding RNA mediates transcriptional silencing by targeting to the perinucleolar region. Mol. Cell. Biol. 28, 3713-28

113 Kanduri, C. (2011) Kcnq1ot1: a chromatin regulatory RNA. Semin. Cell Dev. Biol. 22, $343-50$

114 Mao, Y.S. et al. (2011) Biogenesis and function of nuclear bodies. Trends Genet. 27, 295306

115 Ulianov, S. V et al. (2015) Nuclear compartments, genome folding, and enhancerpromoter communication. Int. Rev. Cell Mol. Biol. 315, 183-244

116 Meng, F. et al. (2015) Compartmentalization and Functionality of Nuclear Disorder: Intrinsic Disorder and Protein-Protein Interactions in Intra-Nuclear Compartments. Int. J. Mol. Sci. 17, 24

117 Sawyer, I.A. et al. (2018) Membraneless nuclear organelles and the search for phases within phases. Wiley Interdiscip. Rev. RNA DOI: 10.1002/wrna.1514

118 Darling, A.L. et al. (2018) Intrinsically Disordered Proteome of Human Membrane-Less Organelles. Proteomics 18, e1700193

119 Uversky, V.N. (2017) Protein intrinsic disorder-based liquid-liquid phase transitions in biological systems: Complex coacervates and membrane-less organelles. Adv. Colloid Interface Sci. 239, 97-114

120 Ishov, A.M. et al. (1999) PML is critical for ND10 formation and recruits the PMLinteracting protein daxx to this nuclear structure when modified by SUMO-1. J. Cell Biol. $147,221-34$

121 Bond, C.S. and Fox, A.H. (2009) Paraspeckles: nuclear bodies built on long noncoding RNA. J. Cell Biol. 186, 637-44

122 Falahati, H. et al. (2016) Nucleation by rRNA Dictates the Precision of Nucleolus Assembly. Curr. Biol. 26, 277-85

123 Feric, M. et al. (2016) Coexisting Liquid Phases Underlie Nucleolar Subcompartments. 
Cell 165, 1686-97

124 Brégnard, C. et al. (2014) DNA damage repair machinery and HIV escape from innate immune sensing. Front. Microbiol. 5, 176

125 Mayer, C. and Grummt, I. (2005) Cellular stress and nucleolar function. Cell Cycle 4, $1036-8$ 


\section{Outstanding Questions}

- Accumulation and sequestration of different proteins with non-canonical functions influences or/and regulates canonical function of nucleoli. Is it possible to regulate these processes to develop novel therapeutic strategies?

- Is it possible to block stress response mediated by nucleoli in order to increase the efficacy of anticancer drugs?

- How were non-canonical functions of nucleoli modified during evolution? Was the evolution of the nucleolus (e.g., transition from bipartite to tripartite organization) connected with modification of its non-canonical functions?

- What is the functional context of DNA-DNA contacts between rDNA and the rest of the genome? How these contacts change during development, pathology or stress?

- It is unclear how transcriptionally active regions are functionally maintained within heterochromatin-rich NADs. CTCF, a protein involved in chromatin domain maintenance and associated with the nucleoli, may play a role in this process. 
Rebuttal letter

Editor comments:

1.The abstract is currently over the 120 word limit that is set for Trends reviews; therefore, please consider this trimmed abstract below. Please make any changes you feel are necessary. The abstract was trimmed. We accepted most of your corrections.

2.Much of this discussion lists interactions, but it may be unclear to general readers what the significance of these interactions are for DNA repair and ribosome biogenesis. Please consider a table that lists these interactions and please consider some of the changes below to make clear the significance of these different PTMs and protein-protein interactions are for the cell. Please make any additional changes you feel are necessary and please ensure the changes made remain scientifically accurate.

We have added two tables listing the interactions of different proteins with the nucleolus and have rewritten the section on protein shuttling for clarity.

3. The subheadings could be shortened to just name the nuclear process that is being described as the earlier subheading makes clear that proteins are shuttling during these events. Please consider the trimmed headings provided.

We now use short headings throughout the text

\section{We have addressed remarks 4-10 in a new version of the section.}

11. Please consider a final concluding sentence that best summarizes the main conclusion from this section.

A conclusion was added to the section on page 8: "In summary, DNA damage triggers an intense protein shuttling between the nucleolus and the nucleoplasm. Release of DNA repair factors stored in the nucleolus as well as bona fide nucleolar proteins into the nucleoplasm stimulates DNA repair."

12. Please clarify what this fact has to do with its relocalization during DNA repair?

NPM1 relocalization upon DNA damage is indeed linked to its functions in DNA repair. This is now stated in the text on page 8: "In particular, NCL translocates into the nucleoplasm and forms foci at sites of DSB repair where NCL is implicated in chromatin remodelling as a histone chaperone [38-41].”

13. Is it possible to speculate on why there is a need for both nucleolar proteins to translocate and DNA repair components to translocate to nucleolus? Is there a context dependency on when this happens? Please consider going into a bit more detail as to the significance of these exchanges for particular types of repair.

We have added a discussion on significance of shuttling of DNA repair proteins between the nucleoplasm and the nucleolus on page 6: "In some cases, the appearance of strong retention centres outside of the nucleolus (e.g. recruitment of DNA repair machinery to DNA lesions) 
may lead to a decrease in the concentration of a protein within the nucleolus. Inversely, sequestration of various enzymes involved in stress response, DNA repair, cell cycle progression etc. within the nucleolus appears advantageous because it allows to keep the concentration of these proteins in the nucleoplasm relatively low under normal conditions and to increase it sharply upon stress. Excessive concentration of DNA repair enzymes and stress response factors in the nucleoplasm under normal conditions may result in a significant offtarget activity. It seems thus logical to store these proteins within a dense phase-separated compartment until they become necessary to fulfil their specific functions [22]. “

14. It is a bit unclear how this connects the two. Does DNA repair impact on ribosome biogenesis or is it just the co-opting of ribosome proteins during times of cellular stress from DNA damage? Please consider clarifying this link.

We believe that there is a link between cellular stress and the ribosome biogenesis. In many cases, ribosome biogenesis stops upon cellular stress and the nucleosomal proteins are reallocated to other nuclear functions. This is now stated in the Conclusions on page 16: "The key role of nucleolus as a regulatory hub is directly related to its main function, production of ribosomes. This process consumes more than a half of cell energy resources and thus should be coordinated with the actual needs of the cell in the ribosomes. Accordingly, many regulatory circuits link the production of ribosomes to the cell cycle progression which, in turn, can be blocked by stress responses. It is thus not surprising that nucleolus acquired a role of regulatory hub connecting many functional processes. The fundamental link between ribosome biogenesis and cell cycle progression is accomplished through involvement of certain proteins in cell cycle control and stress response on the one hand, and the regulation of ribosomal gene transcription and ribosome assembly on the other hand. Many of these proteins are sequestered within phase-separated nucleoli but may shuttle to nucleoplasm in response to various stimuli."

15. Please clarify the major function of telomerase for general readers who may not be aware. We have introduced a short description of telomerase functions on page 9: "Telomerase is a ribonucleoprotein complex associated with the telomere repeats which protects the ends of the chromosomes from degradation. Telomerase contains the telomerase reverse transcriptase (TERT), telomerase RNA, and several additional proteins."

16. Is telomerase involved in DNA repair?

In fact, telomerase protects chromosome ends from DNA repair machinery in order to avoid chromosome fusions via NHEJ of telomeric regions. This is now mentioned on page 9: "Retention of telomerase within the nucleolus is favorable in case of DNA damage as loosening of telomere structure should be necessary for DSB repair at telomeres [45].”

17. Does this occur in the nucleoli, independent of its function at telomerase? Please clarify. TRF2 binds rDNA and promotes rRNA transcription independently of its function on telomeres.

18. It may be unclear how this relates back to its role in the nucleolus vs. nucleoplasm, where it interacts with telomerase. Please clarify. 
We have removed the section on TRF1.

19. Since this discussion is fairly vague and the primary functions of this movement are still unknown, please consider removing this discussion from the main text. Instead, it could be discussed briefly in the concluding remarks to provide future directions for looking at the role of other proteins that shuttle between these compartments.

We have removed the part on Cajal bodies.

20.This section lists lots of examples of proteins that are sequestered into the nucleolus, but it is not clear why they are being sequestered and the role that the nucleolus plays in keeping these proteins there. Is there a general themelfunction of the nucleolus in sequestering these proteins? Please consider adding to this introduction paragraph to provide more context around the function of this sequestration. Please consider the changes made to the introduction to highlight some of the major roles of the nucleolus is sequestration. Since most of the discussion revolves around aggresomes, please consider removing the subheadings and keeping the discussion together under one heading. Please ensure the scientific meaning has remained intact in this new section.

The section was rewritten, and the subheadings were removed.

21. Since this question isn't actually addressed or answered directly in the manuscript, please consider a new heading that better reflects the content of the section. For example, the heading could read: Sequestration of nuclear and cytoplasmic proteins in the nucleolus.

We changed the heading of the section as proposed.

22. Can you please cite the appropriate literature that supports this work?

We now cite literature on aggresome correlation with cell survival on page 11.

23. It may not be clear to general readers the significance of polyA RNAs vs rRNAs in this scenario.

We changed the phrase on page 11 as follows: "These inclusions form so-called 'aggresomes' [23] or 'detention centers' [24] within or in a close contact with the nucleoli (Figure 2); they are rich in protein and RNA [72]. Aggresome formation correlates with cell survival [73].”

24. Is this process a direct formation as opposed to a translocation of the aggregates to the nucleoli as above?

This is indeed a distinct process. We changed the phrase on page 11 to reflect this fact: "Protein aggregates may also form directly in the nucleoli when proteasome function is inhibited. [71].”

25. Please consider going into detail what the specificity of this sequestration is as it may not be clear how these proteins are different from those stated above that are retained.

The key difference is that they are not part of aggresomes and that their sequestration is dependent on the presence of a specific sequence. We changed the phrase on page 11 
accordingly: "Immobilization of these proteins inside the nucleolus is driven by specific nucleolar detention signals (NoDS) [74].”

26. Are functional roles known for other proteins that are retained? Is it possible to provide an over-arching function for this sequestration here?

Functional roles of sequestration were added for other proteins as well.

27. It may be unclear to general readers how this discussion relates to the above discussion on aggregates. Is $p 21$ an aggregate? In addition, the discussion on p21 appears to more directly relevant to the discussion under DNA damage described above

We moved the discussion of p21 to the DNA repair section.

28. Please provide a concluding sentence that best encapsulates the main points of this manuscript.

The following concluding sentence was added: “Importantly, key nucleolar proteins $\boldsymbol{F B L}$, NPM1, and NOPP140 that do not contain these signals remain mobile and evade retention, highlighting the specificity of this nucleolar sequestration [24].”

29. Is it known what unique feature of the nucleolus accounts for this segregation? Please clarify, thank you.

We have extended the discussion on the role of the nucleolus is silencing of perinucleolar chromatin.

30. Can you please cite the appropriate literature that supports this work?

Relevant publications were cited.

31. How does the findings above on NADs and TADs relate to this conclusion that nucleolus interactions can stabilize these contacts? Please consider clarifying this mechanism further. We have extended the discussion on NADs and TADS on page 14.

32. Much of this discussion appears to be directly related to the regulation of chromatin organization and function and therefore directly relevant to much of the discussion above. Please consider integrating this discussion with that above to provide readers with an overall view of how the nucleolus can support $3 D$ genome organization, of which one major function appears to be anchoring.

The two sections were integrated.

33. Please consider adding an introductory sentence that briefly encapsulates the main function of the nucleolus that will be discussed here rather than jump into studies on NADs. This will help readers understand what the major focus of this section is on and why.

The following introductory sentence was added to the section on page 13: "What is the functional significance of NADs and how the nucleolus can regulate their functions?” 
34. Please consider expanding the concluding remarks to discuss future directions for the field in the different areas that have been discussed such as in protein shuttling and chromatin organization. What are the outstanding questions that need to be addressed and how can new tools ensure they are addressed. In addition, please cite the outstanding questions box in this section.

The section was expanded, with a reference to the outstanding questions box.

Thank you for editing the MS. We have accepted most of your suggestions. As we have significantly corrected the MS, we provide a marked-up version of the corrections made in the MS.

\section{Reviewer's comments}

1.Most of the review is represented by a list of results of previous studies (e.g. DNA repair sections, telomere section, stress dependent response section) that is very difficult to follow for the non specialised reader This is the major problem with this manuscript, where a real effort to make all the available informations organic and useful for the reader is lacking. I believe that the Authors should do this effort reorganising the manuscript and providing a general introduction of the processes in which the nucleolus is involved and a sort of map/scheme showing all the functions (including canonical ones) to give a general picture of the issue..

We have reorganized the MS and completely rewritten the section on protein shuttling between the nucleolus and the nucleoplasm for clarity.

2. Some concepts are omitted only shortly mentioning previous reviews (e.g. nucleolus and stress response, the RPs-MDM2-p53 axis). I think that for the reader's sake these concepts should be briefly explained as they provide a paradigm on how non-canonical-ribosome biogenesis unrelated-function are organised in the nucleolus). In addition, the role of non coding RNAs is only marginally considered.

We have added a description of the nucleolus and stress response, the RPs-MDM2-p53 axis on page 10. We were unfortunately limited by a format imposed by the journal concerning an extended description of the relationship between the nucleolus and the non-coding RNAs.

page 5 Nucleolus id a liquid drop... (provide reference in the text) We have added the reference in Box1.

Page 9 Telomerase is composed...: note that among the additional proteins that bind telomerase complex there are the 4 core proteins of the pseudouridylation complex which are the same that are highly aboundant in the nucleolus since they drive site specific, SNORNA guided uridine isomerization.

We thank the reviewer for this remark. This was added to the text on page 9 as follows:

"Telomerase is assembled in the nucleolus by several proteins including dyskerin that later becomes a part of telomerase in the nucleoplasm [44]. Dyskerin also participates in 
pseudouridylation of specific residues in newly synthesized ribosomal RNAs and snRNAs [45].”

pag 13 nucleolus-associated chromatin domains (NADs): there's a typo here, then line below "parms of acrocentric..." please define it as the short arm (easier for the reader) The typo was corrected

page 14: define $\mathrm{Hi}-\mathrm{C}$

$\mathrm{HiC}$ is now defined in the glossary on page 3

concluding remarks: this is more a summary of the review (and can be used in a presentation/general introduction)

Concluding remarks were rewritten. 


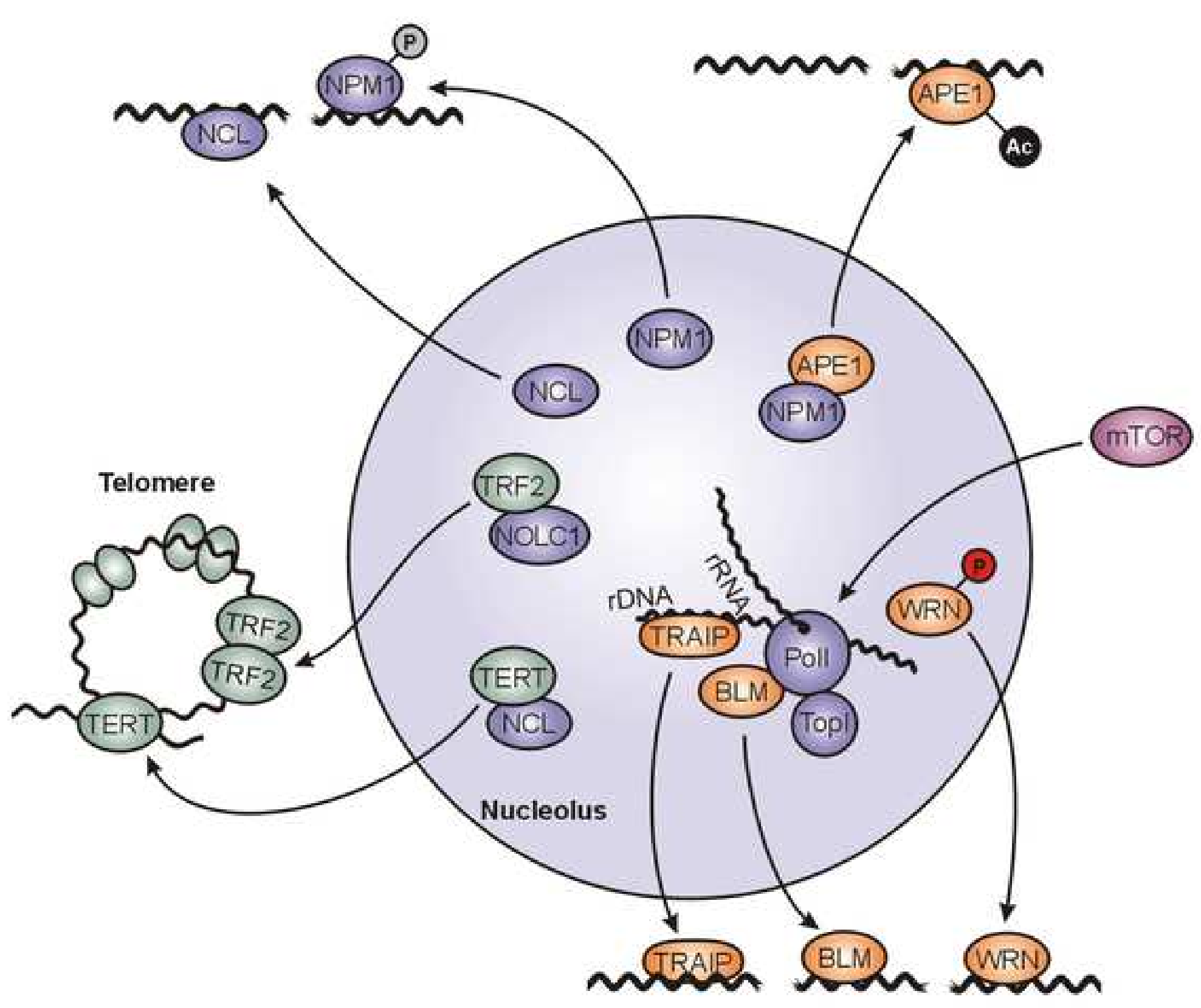


Click here to access/download;Figure;Figure 2 R1.tif $\underline{\underline{ }}$

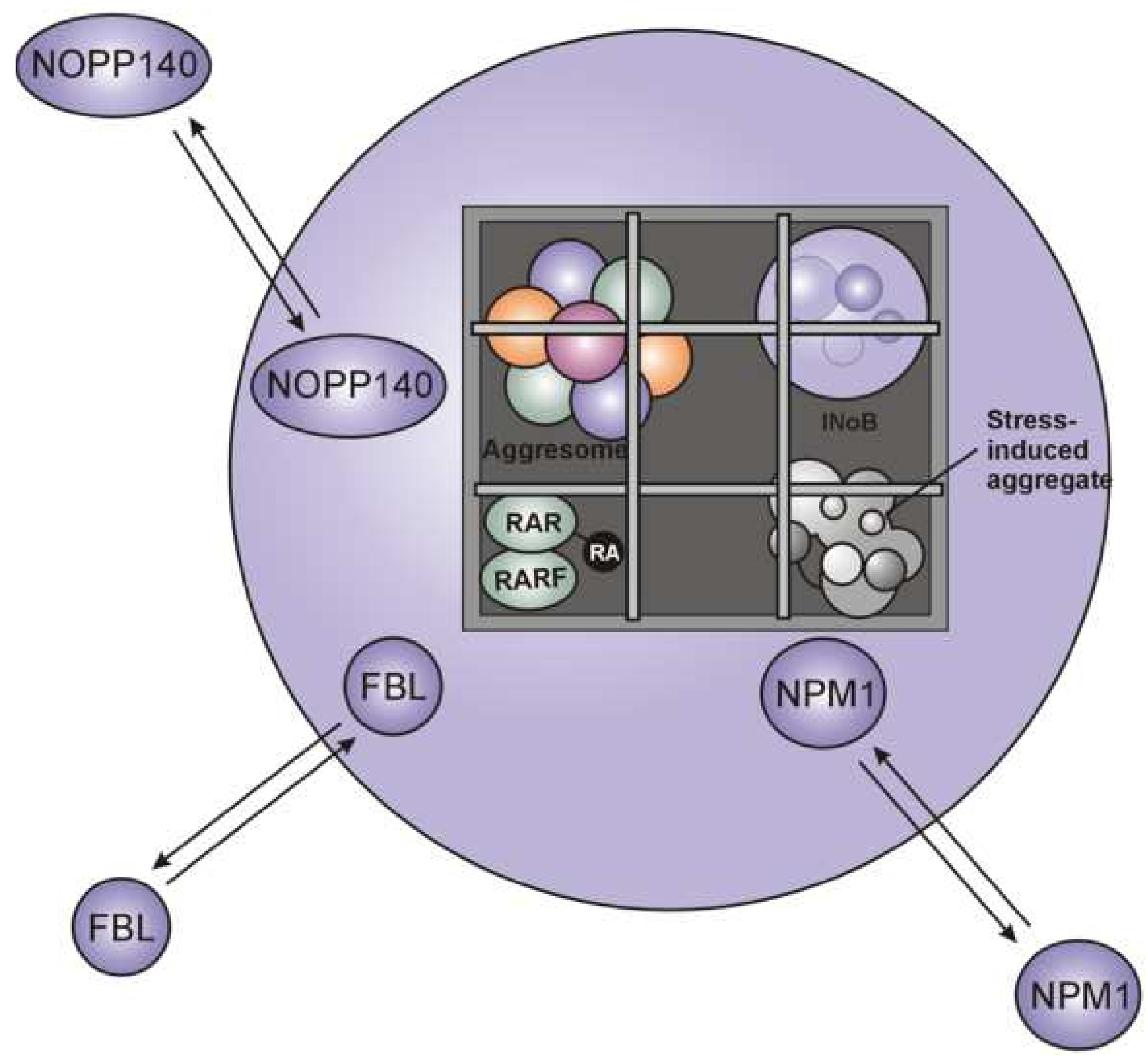




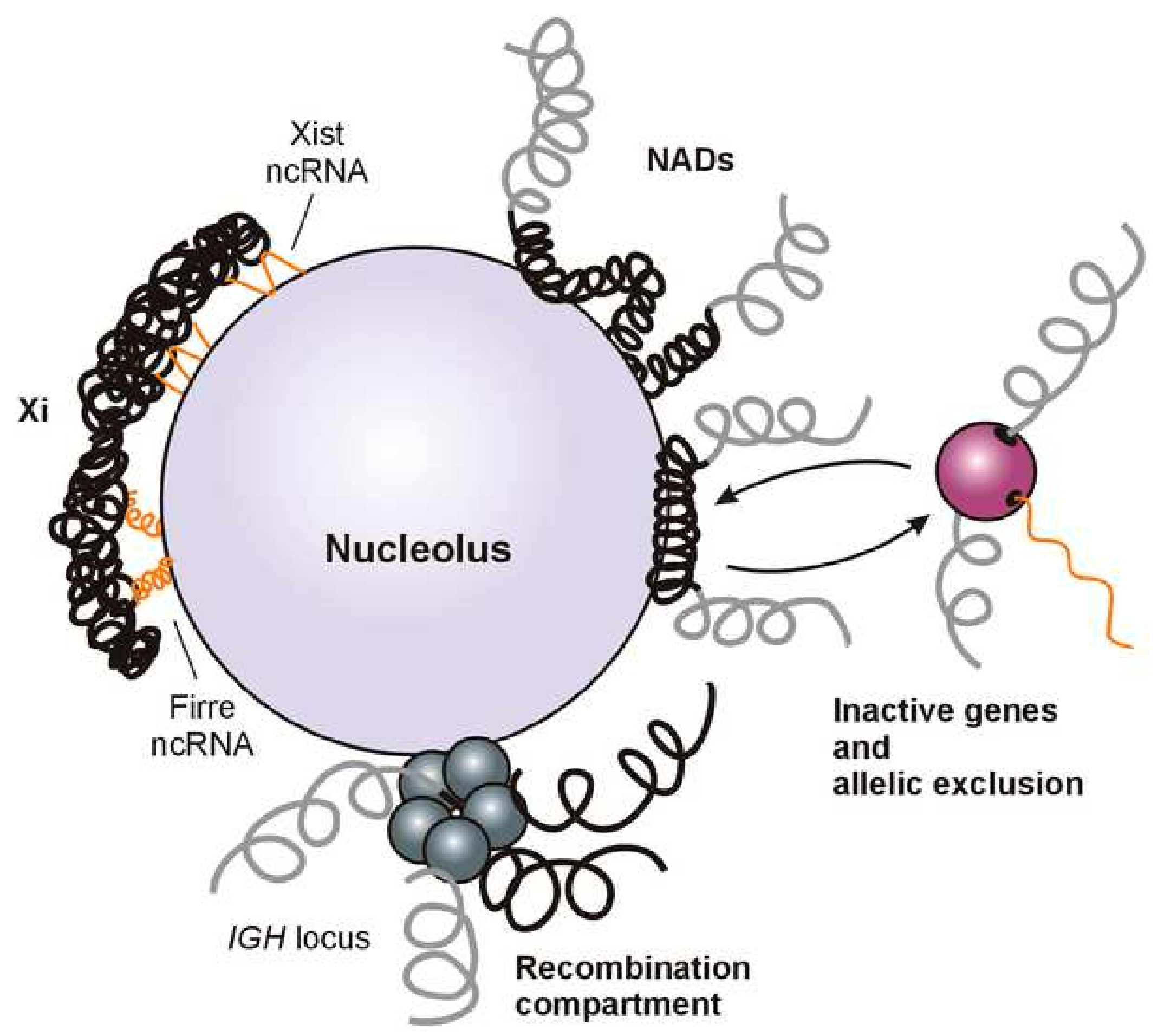


Click here to access/download

\section{Proposed Cover Image Cover image .tif}


Table 1. Examples of nucleoplasmic proteins with a moonlighting function in the nucleolus

\begin{tabular}{|c|c|c|c|}
\hline Protein & Function in the nucleoplasm & Function in the nucleolus & References \\
\hline APE1 & rDNA quality control & DNA repair & [1] \\
\hline ATM & $\begin{array}{l}\text { Activation of checkpoint } \\
\text { signalling upon DSBs; } \\
\text { vesicle and/or protein transport }\end{array}$ & $\begin{array}{l}\text { rDNA silencing in the presence of } \\
\text { persistent DSBs; } \\
\text { large-scale reorganization of the } \\
\text { nucleolar architecture }\end{array}$ & {$[2]$} \\
\hline BLM & DNA repair & pre-rRNA synthesis & {$[3]$} \\
\hline c-myc & $\begin{array}{l}\text { Activation of transcription of } \\
\text { growth-related genes }\end{array}$ & $\begin{array}{l}\text { Attachment of rDNA to the } \\
\text { nucleolar matrix via the IGS } \\
\text { region }\end{array}$ & [4] \\
\hline CTCF & $\begin{array}{l}\text { Three-dimensional } \\
\text { organization of chromatin, } \\
\text { gene regulation as repressor or } \\
\text { activator }\end{array}$ & $\begin{array}{l}\text { Regulation of chromatin at the } \\
\text { rDNA spacer promoter }\end{array}$ & [5] \\
\hline Core histones & $\begin{array}{l}\text { Sequestration of histones in the } \\
\text { nucleolus }\end{array}$ & Chromatin organization & {$[6][7]$} \\
\hline Ku70 & $\begin{array}{l}\text { Non-homologous end joining; } \\
\text { telomere maintenance }\end{array}$ & $\begin{array}{l}\text { Degradation of PICT-1; } \\
\text { regulation of the RPL11-MDM2- } \\
\text { p53 pathway }\end{array}$ & [8] \\
\hline Lamin B2 & $\begin{array}{l}\text { Component of the nuclear } \\
\text { lamina; participates in } \\
\text { anchoring of chromatin at the } \\
\text { nuclear periphery }\end{array}$ & $\begin{array}{l}\text { Interaction with NCL and NPM; } \\
\text { maintenance of morphology of } \\
\text { the nucleolus; } \\
\text { repression of rRNA transcription }\end{array}$ & [9] \\
\hline p53 & $\begin{array}{l}\text { Tumour suppression; } \\
\text { Induction of growth arrest or } \\
\text { apoptosis; } \\
\text { cell cycle regulation }\end{array}$ & Repression of rRNA transcription & {$[10,11]$} \\
\hline PARP1 & $\begin{array}{l}\text { Poly-ADP-ribosylation of } \\
\text { proteins; } \\
\text { DNA repair; } \\
\text { transcription regulation }\end{array}$ & $\begin{array}{l}\text { Pre-rRNA processing; post- } \\
\text { transcriptional modifications; } \\
\text { pre-ribosome assembly }\end{array}$ & [12] \\
\hline PIWI & $\begin{array}{l}\text { Repression of transposable } \\
\text { elements; } \\
\text { RNA cleavage. }\end{array}$ & $\begin{array}{l}\text { Restriction of expression of } \\
\text { rDNA in heat shock conditions. }\end{array}$ & [13] \\
\hline RelA & $\begin{array}{l}\text { Component of a NFkB } \\
\text { transcription factor }\end{array}$ & $\begin{array}{l}\text { Triggering of an NPM-dependent } \\
\text { apoptotic pathway. }\end{array}$ & {$[14]$} \\
\hline Topoisomerase II & $\begin{array}{l}\text { Resolution of topological } \\
\text { stress upon transcription and } \\
\text { replication; gene regulation }\end{array}$ & $\begin{array}{l}\text { Three-dimensional organization } \\
\text { of the rDNA chromatin }\end{array}$ & {$[15]$} \\
\hline
\end{tabular}




\begin{tabular}{|l|l|l|l|}
\hline WRN & $\begin{array}{l}\text { DNA repair; } \\
\text { telomere stability; } \\
\text { maintenance of DNA integrity } \\
\text { during replication }\end{array}$ & $\begin{array}{l}\text { Promoter clearance of RNA pol I; } \\
\text { binding to the active fraction of } \\
\text { rDNA in quiescent cells }\end{array}$ & {$[16,17]$} \\
\hline
\end{tabular}

References :

1 Vascotto, C. et al. (2009) APE1/Ref-1 Interacts with NPM1 within Nucleoli and Plays a Role in the rRNA Quality Control Process. Mol. Cell. Biol. 29, 1834-1854

2 Harding, S.M. et al. (2015) ATM Dependent Silencing Links Nucleolar Chromatin Reorganization to DNA Damage Recognition. Cell Rep. 13, 251-259

3 Grierson, P.M. et al. (2012) BLM helicase facilitates RNA polymerase I-mediated ribosomal RNA transcription. Hum. Mol. Genet. 21, 1172-83

4 Shiue, C.-N. et al. (2014) Myc-induced anchorage of the rDNA IGS region to nucleolar matrix modulates growth-stimulated changes in higher-order rDNA architecture. Nucleic Acids Res. 42, 5505-17

5 van de Nobelen, S. et al. (2010) CTCF regulates the local epigenetic state of ribosomal DNA repeats. Epigenetics Chromatin 3, 19

6 Musinova, Y.R. et al. (2011) Nucleolar localization/retention signal is responsible for transient accumulation of histone $\mathrm{H} 2 \mathrm{~B}$ in the nucleolus through electrostatic interactions. Biochim. Biophys. Acta - Mol. Cell Res. 1813, 27-38

7 Safina, A. et al. (2017) FACT is a sensor of DNA torsional stress in eukaryotic cells. Nucleic Acids Res. 45, 1925-1945

8 Chen, H. et al. (2016) PICT-1 is a key nucleolar sensor in DNA damage response signaling that regulates apoptosis through the RPL11-MDM2-p53 pathway. Oncotarget 7, 83241-83257

9 Sen Gupta, A. and Sengupta, K. (2017) Lamin B2 Modulates Nucleolar Morphology, Dynamics, and Function. Mol. Cell. Biol. 37,

10 Budde, A. and Grummt, I. (1999) p53 represses ribosomal gene transcription. Oncogene $18,1119-24$

11 Kruger, T. and Scheer, U. (2010) p53 localizes to intranucleolar regions distinct from the ribosome production compartments. J. Cell Sci. 123, 1203-1208

12 Boamah, E.K. et al. (2012) Poly(ADP-Ribose) polymerase 1 (PARP-1) regulates ribosomal biogenesis in Drosophila nucleoli. PLoS Genet. 8, e1002442

13 Mikhaleva, E.A. et al. (2019) The nucleolar transcriptome regulates Piwi shuttling between the nucleolus and the nucleoplasm. Chromosome Res. 27, 141-152

14 Chen, J. and Stark, L. (2018) Crosstalk between NF- $\kappa B$ and Nucleoli in the Regulation of Cellular Homeostasis. Cells 7, 157

15 Potapova, T.A. and Gerton, J.L. (2019) Ribosomal DNA and the nucleolus in the context of genome organization. Chromosom. Res. 27, 109-127

16 Sidorova, J.M. (2008) Roles of the Werner syndrome RecQ helicase in DNA replication. DNA Repair (Amst). 7, 1776-1786

17 Rossi, M.L. et al. (2010) Roles of Werner syndrome protein in protection of genome integrity. DNA Repair (Amst). 9, 331-44 
Table 2. Major nucleolar proteins with a moonlighting function in the nucleoplasm.

\begin{tabular}{|c|c|c|c|}
\hline Protein & Function in the nucleolus & Function in the nucleoplasm & References \\
\hline NCL & rRNA processing & $\begin{array}{l}\text { Histone chaperone; } \\
\text { DNA repair; } \\
\text { regulation of gene expression }\end{array}$ & {$[1-4]$} \\
\hline NPM1 & $\begin{array}{l}\text { rRNA processing; } \\
\text { stress sensing }\end{array}$ & $\begin{array}{l}\text { Histone chaperone; } \\
\text { DNA repair; } \\
\text { modulation of p300 activity; } \\
\text { regulation of HMGA; } \\
\text { chromatin remodelling; regulation } \\
\text { of gene expression }\end{array}$ & {$[5-11]$} \\
\hline NPM2 & $\begin{array}{l}\text { Nucleolus maintenance; } \\
\text { perinucleolar heterochromatin } \\
\text { maintenance }\end{array}$ & $\begin{array}{l}\text { Histone chaperone; } \\
\text { chromatin remodelling }\end{array}$ & {$[10,12,13]$} \\
\hline $\begin{array}{l}\text { Ribosomal proteins } \\
\text { L5 and L11 }\end{array}$ & Ribosome biogenesis & p53 activation in stress response & [14] \\
\hline RRL11 & $\begin{array}{l}\text { Ribosome biogenesis; } \\
\text { maintenance of the nucleolar } \\
\text { structure }\end{array}$ & $\begin{array}{l}\text { DNA damage response } \\
\text { upstream regulation of p53 }\end{array}$ & [15] \\
\hline UBTF1 (UBF) & $\begin{array}{l}\text { rRNA transcription ; } \\
\text { maintenance of the nucleolus } \\
\text { integrity }\end{array}$ & $\begin{array}{l}\text { Recruitment of Pol II to histone } \\
\text { gene clusters; } \\
\text { maintenance of the genome } \\
\text { stability }\end{array}$ & {$[16,17]$} \\
\hline
\end{tabular}

\section{References:}

1 Ginisty, H. et al. (2000) Interaction of nucleolin with an evolutionarily conserved pre-ribosomal RNA sequence is required for the assembly of the primary processing complex. J. Biol. Chem. 275, 18845-50

2 Angelov, D. et al. (2006) Nucleolin is a histone chaperone with FACT-like activity and assists remodeling of nucleosomes. EMBO J. 25, 1669-1679

3 Gaume, X. et al. (2011) In vivo Study of the Histone Chaperone Activity of Nucleolin by FRAP. Biochem. Res. Int. 2011, 187624

4 Allinne, J. et al. (2014) Perinucleolar relocalization and nucleolin as crucial events in the transcriptional activation of key genes in mantle cell lymphoma. Blood 123, 2044-53

5 Herrera, J.E. et al. (1995) The ribonuclease activity of nucleolar protein B23. Nucleic Acids Res. 23, 3974-9

6 Yao, Z. et al. (2010) B23 acts as a nucleolar stress sensor and promotes cell survival through its dynamic interaction with hnRNPU and hnRNPA1. Oncogene 29, 1821-34

7 Yang, K. et al. (2016) A redox mechanism underlying nucleolar stress sensing by nucleophosmin. Nat. Commun. 7, 13599

8 Kaypee, S. et al. (2018) Oligomers of human histone chaperone NPM1 alter p300/KAT3B folding to induce autoacetylation. Biochim. Biophys. acta. Gen. Subj. 1862, 1729-1741

9 Arnoldo, L. et al. (2015) A novel mechanism of post-translational modulation of HMGA functions by the histone chaperone nucleophosmin. Sci. Rep. 5, 8552

10 Okuwaki, M. et al. (2012) Function of homo- and hetero-oligomers of human nucleoplasmin/nucleophosmin family proteins NPM1, NPM2 and NPM3 during sperm chromatin remodeling. Nucleic Acids Res. 40, 4861-78

11 Shandilya, J. et al. (2009) Acetylated NPM1 Localizes in the Nucleoplasm and Regulates Transcriptional Activation of Genes Implicated in Oral Cancer Manifestation. Mol. Cell. Biol. 29, $5115-5127$

12 Burns, K.H. et al. (2003) Roles of NPM2 in chromatin and nucleolar organization in oocytes and embryos. Science 300, 633-6

13 Ogushi, S. et al. (2017) Reconstitution of the oocyte nucleolus in mice through a single nucleolar 
protein, NPM2. J. Cell Sci. 130, 2416-2429

14 Bursac, S. et al. (2014) Activation of the tumor suppressor p53 upon impairment of ribosome biogenesis. Biochim. Biophys. Acta 1842, 817-30

15 Dong, Z. et al. (2017) The roles of RRP15 in nucleolar formation, ribosome biogenesis and checkpoint control in human cells. Oncotarget 8, 13240-13252

16 Diesch, J. et al. (2015) Genome wide mapping of UBF binding-sites in mouse and human cell lines. Genomics data 3, 103-5

17 Sanij, E. et al. (2015) A novel role for the Pol I transcription factor UBTF in maintaining genome stability through the regulation of highly transcribed Pol II genes. Genome Res. 25, 201-12 


\section{Membraneless nuclear compartments}

Eukaryotic cell nucleus contains a number of membraneless compartments such as nucleoli, Cajal bodies, PML bodies, nuclear speckles etc. [1]. These compartments are dynamic associates of proteins and nucleic acids and are slightly denser than the bulk of the nucleoplasm. Each type of membraneless compartments is connected to certain functional processes that are not necessarily related to each other [2]. Accordingly, most of the compartments contain a number of various proteins including many moonlighting proteins [3]. The proteins participating in assembly of nuclear compartments frequently possess intrinsically disordered domains [3-5]. These proteins/domains may mediate weak-affinity and non-specific interactions with multiple target sites that trigger the liquid phase separation [6]. The phase-separated droplets accumulate macromolecules that possess an affinity to the components of the droplet interior. Usually a so called platform nucleates the assembly of liquid droplet nuclear compartments. This may be either a protein (e.g. PML in case of PML-bodies [7]) or a non-coding RNA (e.g. NEAT1 RNA in paraspeckles [8] or rRNA in nucleoli [9]). The nucleolus differs from other membraneless compartments in two ways. First, the nucleolus consists of at least three distinct phase-separated layers: droplets within droplets [10]. Second, the availability of pre-rRNAs that constitutes a platform for nucleolus assembly directly depends on the ongoing rDNA transcription [11]. Suppression of rDNA transcription results in full or partial disruption of nucleoli and release into the nucleoplasm or cytoplasm of various proteins sequestered within nucleoli [11]. This is likely to be an important part of the cellular stress response mechanism [12].

\section{Box references}

1 Mao, Y.S. et al. (2011) Biogenesis and function of nuclear bodies. Trends Genet. 27, 295306

2 Ulianov, S. V et al. (2015) Nuclear compartments, genome folding, and enhancerpromoter communication. Int. Rev. Cell Mol. Biol. 315, 183-244

3 Meng, F. et al. (2015) Compartmentalization and Functionality of Nuclear Disorder: Intrinsic Disorder and Protein-Protein Interactions in Intra-Nuclear Compartments. Int. J. Mol. Sci. 17, 24

4 Sawyer, I.A. et al. (2018) Membraneless nuclear organelles and the search for phases within phases. Wiley Interdiscip. Rev. RNA DOI: 10.1002/wrna.1514

5 Darling, A.L. et al. (2018) Intrinsically Disordered Proteome of Human Membrane-Less Organelles. Proteomics 18, e1700193

6 Uversky, V.N. (2017) Protein intrinsic disorder-based liquid-liquid phase transitions in biological systems: Complex coacervates and membrane-less organelles. Adv. Colloid Interface Sci. 239, 97-114

7 Ishov, A.M. et al. (1999) PML is critical for ND10 formation and recruits the PMLinteracting protein daxx to this nuclear structure when modified by SUMO-1. J. Cell Biol. $147,221-34$

8 Bond, C.S. and Fox, A.H. (2009) Paraspeckles: nuclear bodies built on long noncoding RNA. J. Cell Biol. 186, 637-44

9 Falahati, H. et al. (2016) Nucleation by rRNA Dictates the Precision of Nucleolus 
Assembly. Curr. Biol. 26, 277-85

10 Feric, M. et al. (2016) Coexisting Liquid Phases Underlie Nucleolar Subcompartments. Cell 165, 1686-97

11 Brégnard, C. et al. (2014) DNA damage repair machinery and HIV escape from innate immune sensing. Front. Microbiol. 5, 176

12 Mayer, C. and Grummt, I. (2005) Cellular stress and nucleolar function. Cell Cycle 4, 1036-8 
Nucleolus: a central hub organizingfor nuclear functions

Olga V. Iarovaia ${ }^{1,2, *}$, Elizaveta P. Minina ${ }^{3, *}$, Eugene V. Sheval ${ }^{2,4,5, *}$, Daria Onichtchouk ${ }^{6}$, Svetlana

Dokudovskaya $^{2,8}$, Sergey V. Razin ${ }^{1,2,5}$ and Yegor S. Vassetzky ${ }^{2,7,8,9}$

${ }^{1}$ Institute of Gene Biology of the Russian Academy of Sciences, 119334 Moscow, Russia

${ }^{2}$ LIA 1066 LFR2O French-Russian Joint Cancer Research Laboratory, 94805 Villejuif, France

${ }^{3}$ Faculty of Bioengineering and Bioinformatics, Lomonosov Moscow State University, 119991

Moscow, Russia

${ }^{4}$ Belozersky Institute of Physico-Chemical Biology, Lomonosov Moscow State University, 119991

Moscow, Russia

${ }^{5}$ Faculty of Biology, Lomonosov Moscow State University, 119991 Moscow, Russia

${ }^{6}$ Developmental Biology Unit, Department of Biology I, University of Freiburg, Hauptstrasse 1, D-79104 Freiburg, Germany

${ }^{7}$ Koltzov Institute of Developmental Biology of the Russian Academy of Sciences, 119334 Moscow,

Russia

${ }^{8}$ UMR8126, Université Paris-Sud, CNRS, Institut Gustave Roussy, 94805 Villejuif, France

${ }^{9}$ Corrsponding author

*equal contribution

\section{Keywords:}

Nuclear compartmentalization, nucleolus, 3D genome organization, DNA repair and recombination, transcription

Word count: $3906 \underline{3843}$ 


\section{Summary}

The nucleus contains distinct nuclear bodies (NBs); The nucleolus is the largest and the most studied NBnuclear body, but its role in the functioning of the nucleus-nuclear function is far from being fully understood. The-Much work on the nucleolus is not surrounded by a membrane, yet it contains DNA, RNA and a set of proteins that can either be retainedhas focused on its role in the nucleolus or rapidly shuttle between the nucleoplasm, the nucleolus and the cytoplasm in respense to various stimuli. Theregulating RNA polymerase I transcription and ribosome biogenesis; however, emerging evidence points to the central function of the-nucleolus inas an organizing hub for many nuclear functions besides RNA pelymerase I transeription and ribesome biogenesis. Here we discuss the functions of the nucleolus related to theaccomplished via shuttling of proteins and nucleic acids between the nucleolus and nucleoplasm. The functional processesHere we discuss the cellular mechanisms affected by shuttling of nucleolar components that include 3D organization of the genome, stress response, DNA repair and recombination, transcription regulation, telomere maintenance and other essential cellular functions. 


\section{Glossary}

Allelic exclusion: a situation when one allele of a given gene is expressed while the other allele is transcriptionally inactive.

$\underline{\boldsymbol{H} i-\boldsymbol{C}: \text { a high-throughput method to study the three-dimensional architecture of genomes based }}$ on proximity ligation.

Nucleolus-associated domains (NADs): chromatin domains that dynamically interact with nucleoli.

Nucleolar localization signals (NoLS): a short protein sequence allowing to localize a protein inside the nucleolus. NoLS do not have a consensus sequence, but they are constantly enriched with positively charged amino acids. As a result, nucleolar accumulation via NoLS is dependent on the overall charge of the signal region.

Protein shuttling: a majority of bodies, but rather are continuously exchanged between these bodies and the surrounding nucleoplasm. This mobility allows these proteins to quickly relocalize between different nuclear domains, leading to unprecedented plasticity of the genome functioning.

Sequestration: mobile, continuously exchanging proteins can increase their concentration inside a nuclear body under some conditions. This process referred to as protein sequestration may be driven either by appearance of novel binding sites for the protein inside nucleoli, or disappearance of binding sited outside nucleoli, or posttranslational modifications of protein (or a combination thereof). Sequestration may also be due to a decrease of protein exchange due to 
tight association with a component(s) inside any subcellular structure (protein immobilization) or due to formation of protein aggregates.

Stress response: a reaction which dedicates energy and effort to acute adaptation to stress.

Topologically associating domain (TAD): a genomic region where DNA sequences physically interact with each other with an increaseda higher frequency as compared to the sequences outside the TAD. In mammals, TAD boundaries are enriched in CTCF/Cohesin binding sites. Most interactions observed between gene enhancers and promoters occur within one TAD. TADs were shown to coincide with replication domains. 


\section{Introduction}

The main function of the nucleolus is the synthesis and processing of rRNA and ribosome assembly. Nucleoli contain clusters of ribosomal RNA genes (rDNA) and their transcripts (rRNA) (reviewed in [1]), as well as several hundred proteins participating in many nuclear processes inside and outside the nucleolus [2]. Recent-proteomies data on nucleolar proteins and the analysis of genomic DNA loci associated with the nucleolus suggest that the functions of the nucleolus are not limited by ribosome biogenesis. Indeed, chromatin non-randomly associates with the nucleolus and is organized into-so-called nucleolus-associated domains (NADs) $[3,4]$.function of the nucleolus is not limited to ribosome biogenesis, and that the nucleolus plays a role of a central hub regulating many nuclear and cellular processes. Movement of chromatin $v s$. the nucleolus may trigger activation and silencing of gene transcription $[5,6][3,4]$, mediate inactivation of chromatin domains [7] underly allelic exelusion-and spatially organize [5], underlie allelic exclusion, and spatially organize gene recombination [8].[6]. In a similar way, movement of proteins between the nucleolus and the nucleoplasm regulates DNA repair, RNA polymerase II transcription, telomere maintenance, stress response $[9,10][7,8]$, and apoptosis [11]. All these are non canonical functions of the nucleolus; some of them were discovered quite recently. Currently, the molecular mechanisms which allow to engage a large number of components inside nucleoli and the reasons of accumulation of multiple functions inside one organelle remain unclear. Here we discuss the role of protein and nuclear acids shuttling between nucleolus, perinucleolar region and nucleoplasm in mediation of non-canonical functions of the nucleolus. [9]. Dynamic changes in localization of many proteins and chromatin regulated by the nucleolus appears to modulate a multitude of functions that were not previously associated with the nucleolus. These non-canonical functions of the nucleolus were discovered quite recently; therefore, the molecular mechanisms regulating these newly found nucleoli functions and the interactions of various components within the nucleolus remain unclear. 


\section{Mechanisms of Protein accumulation of proteins in the nucleolus}

Nucleolus is a liquid drop nuclear compartment resulting from phase separation (Box 1).

Protein accumulation inside nucleoli is a consequence of affinity interactions with core nucleolar components: rDNA, RNA and nucleolar proteins [12]. This accumulation is driven by short amino acid stretches referred to as nucleolar localisation sequences (NoLS) [13] NoLS substantially enriched with positively charged amino acids. Although there is no NoLS eonsensus sequence, on average, -.50\% of amino acids inside NoLS are lysines and arginines [14]. Lysines and arginines generate a positive charge essential for the nucleolar localization [14 17] Thus, charge-dependent (electrostatic) interactions of amino acid residues with

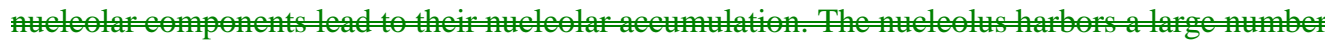
ef negatively charged RNA molecules, potential targets for positively charged NoLS-[17]. NoLS do not interact with DNA since its charge is neutralized in the nucleus by histones, bivalent ions and polyamines $[18,19]$. Nucleolar aceumulation of proteins may also be due to their interaction with a major nucleolar protein NCL (nucleolin or C23), containing long acidic patches that can interact with positively charged NoLS [20]. Nucleolar aceumulation by NoLS can be regulated; this allows proteins to translocate from the nucleolus to the nucleoplasm and vice versa. For example, tumour suppressor ARF inhibits nucleolar import of TTF I, RNA polymerase I transcription termination factor, by binding to its NoLS, thus favouring TTF-I displacement from the nucleolus to the nucleoplasm [21]. This causes the suppression of ribosomal RNA synthesis followed by cell proliferation arrest.

Shuttling of proteins between the nucleolus and the nucleoplasm regulates important nuclear processes

Formatted: Font: Italic

Nucleolus-is a highly dynamic structure, with proteins being actively exchanged between the

Formatted: Font: Bold, Italic, Font color: Auto nucleolus and the nucleoplasm $[22,23]$. In many cases, this protein-shuttling underlies important 
nuclear processes. The equilibrium between the nucleolar and nucleoplasmic localisation of a particular protein may be influenced by posttranslational modifications. In other cases, appearance of strong retention centres outside of the nucleolus (e.g. recruitment of DNA repair machinery to DNA lesions) may be sufficient to decrease the concentration of a protein within the nucleolus. Several examples are discussed below.

DNA-repair is regulated by protein shuttling between the nucleolus and the nucleoplasm.

DNA repair proteins in the nucleolus. Nucleolar proteome contains many DNA binding proteins including those involved in DNA repair such as APE1 [24], WRN [25], ATM, ATR, MRE11, PARP1, TOPBP1, XRCC1, ZRF1 and Ku70/80 [26,27]. Many of these proteins participate both in DNA repair in the nucleoplasm and riboseme biogenesis in the nucleolus (Figure 1). The apurinic/apyrimidinic endodeoxyribonuclease 1 (APEX1; APE1; REF 1) is an essential compenent of base excision repair (BER) machinery, but it also-deletes lesions from rRNA [24]. APE1 interacts with nucleolar proteins NPM1 (also called B23, nucleophosmin, NO38 or numatrin), RPLP0, SA as well as with the 47S, $18 \mathrm{~S}$ and $28 \mathrm{~S}$ rRNAs [28]. The Nterminus of APE1 contains several positively charged lysine residues which modulate interaction of APE1 with NPM1 resulting in APE1 localization in the nucleolus. When some of these lysine residues are acetylated, NPM1 no longer interacts with APE1, and APE1 accumulates in nucleoplasm [24]. A similar mechanism of regulated protein shuttling between the nucleolus and the nucleoplasm (via protein-protein interactions and posttranslational modifications) has been described for RecQ like helicases WRN (Werner syndrome) and BLM (Bloom syndrome). They are implicated in double strand breaks (DSBs) and base lesions repair, resolving stalled replication forks and other forms of replication stress [27,29,30]. However, WRN possesses a NoLS in its $C$ terminus and is accumulated in the nucleolus [25]. When DNA repair is activated, WRN is dephosphorylated and moves from the nucleolus to the nucleoplasm; treatment with a 
tyrosine phosphatase inhibitor maintained the nucleolar localization of WRN [10]. WRN localization can also be modulated by acetylation [31]. BLM can directly bind rDNA and interact with RNA Pol I, thus facilitating pre rRNA synthesis in the nucleolus $[32,33]$. Switching between DNA repair and ribosome biogenesis is likely to occur through protein-protein interactions and posttranslational modifications. BLM interacts with DNA Topoisomerase I in the nucleolus [34] and its localization can also be regulated by ubiquitination [35]. DNA damage response factor NBS1 can transiently accumulate in nucleoli upon inhibition of rDNA transcription. Nucleolar localization of NBS1 depends on its interaction with a nucleolar protein Treacle (TCOF1). The Treacle-NBS1 complex can act as an adaptor for the ATM kinase to phospherylate nucleolar proteins that regulate rDNA transeription in respense to DNA damage. In this case, activation ATMHina in the Treand complex into the nucleolus and thus to sileneing of rRNA transeription [36]. The RING finger protein TRAIP protects genome integrity and its mutation causes primordial dwarfism [37]. TRAIP is possibly accumulated in nucleolus because of interaction with RNA Poll transcripts [38]. However, after exposure of cells to UV, it rapidly migrates to UV-induced DNA lesions in the nucleoplasm.

Aucleolar proteins in DNA repair. While classical DNA repair enzymes can be located in the nucleolus, "typical" nucleolar proteins can be imported to the nucleoplasm for DNA repair. This was described for the major nucleolar proteins, NCL and NPM1 [9]. NCL undergoes a robust yet reversible nucleoplasmic translocation and forms nucleoplasmic foci at sites of DSB repair where NCL is implicated in chromatin remodelling [39-41]. Both NCL and NPM1 are histone chaperones [42 44]. Ionizing radiation, cisplatin or etoposide treatment lead to relocalization of NPM1 from the nucleolus to the nucleoplasm [45]. This relocalization (or retention of NPM1 within the DSB repair foci) is likely to be regulated by phosphorylation. A T199 phosphorylated population of NPM1 is present at DSB foci, while the unmodified protein does not associate with 
DSBs. Replacement of endogenous NPM1 with its non phosphorylable T199 A mutant delayed DNA repair [46]. Both NCL and NPM1 are rapidly exchanged between the nucleolus and the nucleoplasm [47], therefore they can be readily available for DNA repair when necessary. The nucleoplasmic relocalization of NCL and NPM1 may be a part of general cellular stress response $[48,49]$, although the functional significance of this relocalization is to be clarified.

In summary, there is an intensive cross talk between the nucleolus and DNA repair machinery, with protein shuttling between the nucleolus and the nucleoplasm. This connects ribosome biogenesis and DNA repair.

\section{Temome is regulated by shutling of telomerase between nucleolus and} nucleoplasm. Although telomerase executes its major function in the nucleoplasm, it is assembled in the nucleolus [50] and may be temporarily retained there under certain conditions. Telomerase is composed of the telomerase reverse transcriptase (TERT), telomerase RNA, and several additional proteins. Remarkably, TERT contains three NoLS at positions of aa 1-15 [51], $326-620$ [52] and $965-981$ [53]. One of the NoLS coincides with the functional domain of TERT, but the nucleolar localization of TERT appears to be unrelated to its telomerase function [53]. The telomerase is retained in nucleoli through its interaction with NCL [50]. It has been proposed that retention of telomerase within the nucleolus is favorable in case of the necessity to repair DNA DSBs [54]. Of note, TERT performs some moonlight functions in the nucleolus as it binds to rDNA and stimulates RNA PolI transcription in oncogenic and regenerative hyperproliferation, probably via stimulation of the transcription initiation complex formation [55] (Figure 1). The telomeric repeat-binding factors TRF1 and TRF2 interact with telomeres and protect them. TRF2 can be sequestered in the nucleolus affecting its functions at telomeres [56]. Nucleolar localization of TRF2 is promoted by the nucleolar protein NOLC1 [57]. NOLC1 overexpression and consequent relocalization of TRF2 to the nucleoli arrests cell 
eycle in the $G_{\theta}-G_{1}$ phase and prevents proliferation. TRF2 also binds rDNA and promotes rRNA transcription [58]. Activity of TRF1 is modulated by two nucleolar proteins: nucleostemin and guanine nucleotide binding protein like 3 like (GNL3L). GNL3L stabilizes TRF1 [59] while nucleostemin promotes its degradation [60], inhibits TRF1 dimerization and shortens its dynamic association with the telomere [61].

\section{Protein shuttling between the nucleolus, the nucleoplasm and the cytosol in mTOR signalling.}

The nucleolus functions in response to endogenous and environmental signals is connected with another major cellular system that senses various types of stress, the mammalian target of rapamycin (mTOR) pathway, which acts as a central hub integrating intra and extra cellular eues into cell survival and degradation pathways [62]. Although mTOR complex 1 (mTORC1) is predominantly cytosolic and localizes around lysosomal membrane, several members of mTORC1, including mTOR itself, can be as well found in the nucleus and the nucleolus [63-69]. One of the main functions of mTORC1 is activation of anabolic processes, including ribosome The nucleolus is a membraneless organelle that forms through phase separation in the nucleus (Box 1). Protein accumulation inside nucleoli is a consequence of affinity interactions with core nucleolar components: rDNA, RNA and nucleolar proteins [10]. This accumulation is driven by short amino acid stretches referred to as nucleolar localisation sequences (NoLS) [11]. NoLS are substantially enriched with positively charged amino acids. Although there is no NoLS consensus sequence, approximately $50 \%$ of amino acids inside NoLS are lysines and arginines that generate a positive charge essential for nucleolar localization [1215]. Thus, charge-dependent (electrostatic) interactions of amino acid residues with nucleolar components lead to their nucleolar accumulation. The nucleolus harbors a large number of negatively charged RNA molecules, potential targets for positively charged NoLS [14]. Of note, NoLS do not interact with DNA since its charge is neutralized by histones, bivalent ions and polyamines [16,17]. Low specificity of electrostatic accumulation via NoLSs allows a large 
number of proteins to be dynamically accumulated inside nucleoli. Nucleolar accumulation of proteins may also be due to their interaction with some nucleolar proteins including such as NCL (nucleolin or C23) which contains long acidic patches interacting with positively charged NoLS [18]. Nucleolar accumulation by NoLS is dynamic and can be affected by a variety of factors. For example, tumour suppressor ARF inhibits nucleolar import of TTF-I, a RNA polymerase I transcription termination factor, by binding to its NoLS, thus favouring TTF-I displacement from the nucleolus to the nucleoplasm [19] followed by the suppression of ribosomal RNA synthesis and cell proliferation arrest.

\section{Protein shuttling between the nucleolus and the nucleoplasm regulates nuclear processes}

Nucleolus is a highly dynamic structure involved in an active exchange of proteins between the nucleolus and the nucleoplasm (protein shuttling) [20,21]. In some cases, the appearance of $\underline{\text { strong retention centres outside of the nucleolus (e.g. recruitment of DNA repair machinery to }}$ DNA lesions) may lead to a decrease in the concentration of a protein within the nucleolus. $\underline{\text { Inversely, sequestration of various enzymes involved in stress response, DNA repair, cell cycle }}$ progression etc. within the nucleolus appears advantageous because it allows to keep the concentration of these proteins in the nucleoplasm relatively low under normal conditions and to increase it sharply upon stress. Excessive concentration of DNA repair enzymes and stress response factors in the nucleoplasm under normal conditions may result in a significant off-target activity. It seems thus logical to store these proteins within a dense phase-separated compartment until they become necessary to fulfil their specific functions [22].

The unique feature of the nucleolus is that it is both a storage place and a stress sensor. Some proteins are stored in the nucleolus irreversibly $[23,24]$. Other proteins perform major functions within the nucleolus and a moonlighting function in the nucleoplasm (Table 1). The third group of proteins have their main function in the nucleoplasm, but they are stored in the nucleolus until 
release (Table 2). Shuttling control is tightly connected with rDNA transcription and modulated by stresses, cell cycle progression, energy resources and various post-translational modifications. Below we discuss several examples demonstrating how the nucleolus integrates external signals and provides necessary responses to different stimuli.

$\underline{\underline{D N A}}$ damage and repair. Cells are subjected to a multitude of DNA lesions resulting from oxidation, alkylation, exposure to UV light or irradiation. The response to these events may include DNA repair and cell-cycle arrest. The nucleolus plays an important role in DNA repair as it contains many DNA-binding proteins involved in DNA repair in the nucleoplasm and $\underline{\text { ribosome biogenesis in the nucleolus (Table 1, Figure 1). Switching between ribosome }}$ biogenesis and DNA repair functions is likely to occur through protein-protein interactions and posttranslational modifications regulating shuttling. For example, the apurinic/apyrimidinic endodeoxyribonuclease 1 (APE1; APEX1; REF-1) interacts with several nucleolar proteins via positively charged N-terminal lysine residues. In the nucleolus, APE1 interacts with NPM1 (also called B23, nucleophosmin, NO38 or numatrin), the 47S, $18 \mathrm{~S}$ and $28 \mathrm{~S}$ rRNAs [25] and deletes lesions from rRNA [26]. Deacetylation of N-terminal lysine residues upon DNA damage results in APE1 relocalization in the nucleoplasm where it is an essential component of base-excision repair machinery [26]. Another example concerns RecQ-like helicases WRN (Werner syndrome) and BLM (Bloom syndrome) implicated in double strand break (DSB) and base lesion repair in the nucleoplasm [27-29]. Phosphorylation [8], acetylation [30] and ubiquitination [31] of WRN and BLM regulates their shuttling between the nucleolus and nucleoplasm. WRN possesses a

NoLS in its C-terminus and is normally located in the nucleolus where it interacts with RNA Pol I; the absence of WRN in the nucleolus reduces $18 \mathrm{~S}$ and $28 \mathrm{~S}$ rRNA levels [32]. When DNA repair is activated, WRN is dephosphorylated and moves from the nucleolus to the nucleoplasm [8]. This process is also modulated by acetylation [30]. In the nucleolus, BLM facilitates pre$\underline{\text { rRNA synthesis by directly binding rDNA and interacting with RNA Pol I and DNA }}$ 
topoisomerase I [33-35]. BLM ubiquitination promotes its recruitment to DNA lesions while the absence of the RNF8 ubiquitin ligase results in its nucleolar sequestration [31].

$\underline{\text { Some proteins move into the nucleolus upon DNA damage: for example, a nucleoplasmic DNA }}$ damage response factor NBS1 can transiently accumulate in the nucleolus to inhibit rDNA $\underline{\text { transcription. Nucleolar localization of NBS1 depends on its interaction with the nucleolar }}$ protein Treacle (TCOF1). The Treacle-NBS1 complex acts as an adaptor for ATM kinase, which phosphorylates nucleolar proteins that regulate rDNA transcription in response to DNA damage. Activation of ATM kinase in the nucleus leads to translocation of the Treacle-NBS1 complex into the nucleolus and thus to silencing of rRNA transcription [36].

$\underline{\text { Similarly to many classical DNA repair enzymes located in the nucleolus, major nucleolar }}$ proteins NCL and NPM1 are rapidly exchanged between the nucleolus and the nucleoplasm so they can be readily available for DNA repair when necessary (Table 2, Figure 1) [7,37]. In particular, NCL translocates into the nucleoplasm and forms foci at sites of DSB repair where NCL is implicated in chromatin remodelling as a histone chaperone [38-41]. Relocalization of NPM1 from the nucleolus to the nucleoplasm is induced by DNA damaging agents such as ionizing radiation, cisplatin or etoposide treatment [42]. The relocalization of NPM1 to DSB repair foci is regulated by its phosphorylation [43]. In summary, DNA damage triggers an intense protein shuttling between the nucleolus and the nucleoplasm. Release of DNA repair factors stored in the nucleolus as well as bona fide nucleolar proteins into the nucleoplasm stimulates DNA repair.

Telomere maintenance. Telomerase is a ribonucleoprotein complex associated with the telomere repeats which protects the ends of the chromosomes from degradation. Telomerase contains the $\underline{\text { telomerase reverse transcriptase (TERT), telomerase RNA, and several additional proteins. }}$ 
Telomerase is assembled in the nucleolus by several proteins including dyskerin that later becomes a part of telomerase in the nucleoplasm [44]. Dyskerin also participates in pseudouridylation of specific residues in newly synthesized ribosomal RNAs and snRNAs [45]. Telomerase may be temporarily retained there under certain conditions through its interaction with NCL [46]. Retention of telomerase within the nucleolus is favorable in case of DNA damage as loosening of telomere structure should be necessary for DSB repair at telomeres [47]. Remarkably, TERT contains three NoLS [48-50]. TERT in the nucleolus stimulates RNA PolI $\underline{\text { transcription and binds rDNA during oncogenic and regenerative hyperproliferation, probably via }}$ activation of the transcription initiation complex formation [51] (Figure 1). The telomeric repeatbinding factor TRF2 also interacts with telomeres and protects them. TRF2 can be sequestered in the nucleolus by nucleolar protein NOLC1 [52], thereby affecting its function at telomeres [53]. NOLC1 overexpression and consequent relocalization of TRF2 to the nucleoli arrests cells in $\mathrm{G}_{0}-$ $\underline{\mathrm{G}}_{1}$ phase and prevents proliferation. In the nucleolus,TRF2 binds rDNA and promotes rRNA transcription [54].

Nucleolus and stress response. Although most nucleolar proteins are highly dynamic and shuttle between the nucleolus and the nucleoplasm $[37,55,56]$, these proteins can be retained in the nucleolus during transcriptional, acidic, or heat stress. Disruption of protein traffic through the nucleolus may lead to formation of intranucleolar protein complexes. One example is a cyclindependent kinase inhibitor p21cip (or p21), present both in the nucleus and the cytoplasm. In the cytoplasm, p21cip has oncogenic properties, while nuclear p21cip is a tumour suppressor. p21cip transits through the nucleolus on its way from the nucleus to the cytoplasm. DNA damage inhibits this transit and induces formation of p21 cip-containing intranucleolar bodies (INoBs) [57]. These structures also contain SUMO-1 and UBC9, the E2 SUMO-conjugating enzyme, $\underline{\text { several DNA damage checkpoint proteins and cell cycle regulators Cdk2, Cyclin E, PCNA, p53 }}$ and MDM2 [58]. SUMO-1 and p21cip control the transit of proteins through the nucleolus, but 
when nucleolar export is disrupted by DNA damage, these proteins act as scaffolds that mediate the formation of the multiprotein complex in the nucleolus [58]. The MDM2-p53 pathway which coordinates cellular response to stress is also regulated by shuttling of the nucleolar proteins. In response to stress, several nucleolar proteins, including NCL [59], NPM [60], and nucleostemin [61], are released into the nucleoplasm, where they bind to and inhibit MDM2 resulting in p53 activation and stabilization (Figure 2).

Mammalian target of rapamycin (mTOR) pathway is another major cellular system that senses various types of stress and integrates intra- and extra-cellular cues for cell survival and degradation pathways [62]. One of the main functions of mTORC1 is activation of anabolic processes, including ribosome biogenesis and translation. $\mathrm{mTORC} 1$ affects nucleolar transcription through its downstream effector p70 S6 kinase 1, which in turn phospherylates a number of its own effectors important for translation initiation [70]. Remarkably, nuclear mTOR protein can bind to theusands of sites in the genome $[66,67]$ and interact with rDNA chromatin either directly [63-65] or via modulation of other rDNA-interacting factors [71,72]. Treatment with mTORC1 inhibitor rapamycin prevents mTOR localization to the nucleolus and interferes with the processing of ribosomal rRNAs [68]. One of the recent examples of the nucleolar activity of mTORC1 is related with the function of inhibitor of growth $1 \mathrm{~b}$ protein (ING1b), which associates with $\mathrm{rDNA}$ repeats and is required for the efficient recruitment of chromatin regulator HDAC1 to the nucleoli [69]. ING1 reduces mTOR localization to the nucleolus and promotes recruitment of HDAC1 to the NoRC complex and to major Pol I transcription factor UBF1. Reversibly, knockdown of ING1 results in the accumulation of mTOR in nucleolus and it asseciation with UBF1.

Temporary repositioning of Cajal bodies into the nucleolus. Cajal bodies are highly mobile structures moving throughout the nucleoplasm, but they have also been detected within the 
nucleolus in human breast carcinoma cells, brown adipocytes and hepatocytes of hibernating dormice $[73,74]$. Several observations show that Cajal bodies have the ability to move to and from the nucleolar periphery and within the nucleolus [75]. The functional significance of these unusual shuttling of one membraneless compartment in and out of another compartment is eurrently unknown.

\section{Does the nucleolus serve as a nuclear «prisen»?}

Recent studies indicate that the nucleolus can be used for temporary storage or even exclusion from circulation of various nuclear and even cytoplasmic proteins.

Intranucleolar bodies and aggresomes. Misfolded proteins are cleared from cells by the ubiquitin proteasome system, preventing cell death induced by the proteotoxic stress. When this system is inhibited or impaired, misfolded proteins aggregate and form proteinaceous particles that are transported into the perinucleolar region to form so-called 'aggresomes' [76] or 'detention centers' [77] within or in a close contact with the nucleoli (Figure 2). These inclusions are rich in proteins and RNAs, but, surprisingly, nucleolar aggresomes do not contain rRNAs, an abundant component of the nucleoli, but rather polyadenylated RNAs (polyA RNAs) [78]. Protein aggregates may also be formed in the nucleoli of proteasome inhibitor treated cells [79]. The aggresome formation correlates with cell survival. Aggresomes are cleared from cells by aggrephagy, a selective autophagic process. Disruption of the protein traffic through the nucleoli may also lead to formation of intranucleolar protein complexes. p21cip (or p21) is a eyclin-dependent kinase inhibitor present both in the nucleus and the cytoplasm. In the eytoplasm, p21 has oncogenic properties, while nuclear p21 is a tumour suppressor. p21Cip1 transits through the nucleolus on its way from the nucleus to the cytoplasm. DNA damage inhibits this transit and induces formation of p21Cip1 containing intranucleolar bodies (INoBs) [80]. These structures also contain SUMO 1 and UBC9, the E2 SUMO-conjugating enzyme, 
several cell cycle regulators and DNA damage checkpoint proteins Cdk2, Cyclin E, PCNA, p53 and MDM2 [81]. It seems that SUMO-1 and p21 regulate the transit of proteins through the nucleolus, but when nucleolar export is disrupted by DNA damage, these proteins play the role of scaffold that mediate formation of multiprotein complex in the nucleolus [81].

Sequestration of transcription factors in the nucleolus. TATA-binding protein (TBP)-related factor 2 (TRF2) is a RNA polymerase II transcription factor. During interphase, TRF2 is located almost exclusively in the nucleolus in HeLa and Cos cells and is rapidly released from the nucleolus upon inhibition of RNA Pol I transcription [82]. Another example of sequestration, Retinoic acid receptor ( $R A R)$, interacts with retinøic acid $(R A)$ which is widely used for treatment of various cancers such as acute promyelocyte leukemia. However, tumour cells become resistant to this drug through modulation of expression levels of a specific repressor known as the RA resistance factor (RaRF). RaRF directly interacts with RAR and sequesters it into the nucleolus in response to RA, thereby contributing to loss of RA sensitivity [83].

Stress-dependent retention of proteins in the nucleolus. The role of the nucleolus in the stress response has been reviewed recently $[84,85]$. Without intention to repeat the analysis presented in these reviews, we shall address here only topics closely related to the subject of our discussion. Although most of nucleolar proteins are highly dynamic and shuttle between the nucleolus and the nucleoplasm in living cells $[47,86,87]$, some proteins can be captured and retained inside the nucleolus under stress conditions. Transcriptional, acidic or heat stress leads to expression of specific lncRNAs from the intergenic spacer separating individual rDNA transcription units (IGS IncRNAs) [88]. These transcripts capture and immobilize inside nucleoli several important proteins, including von Hippel Lindau (VHL) protein, DNA (cytosine-5) methyltransferase 1 (DNMT1), the $\delta$ catalytic subunit of DNA polymerase (POLD1), Hsp70, RNF8, MDM2, and APC2 [88], RPA16 and RPA40, PES1, NOP52, RRP1B, NOM1, NOL1, and 
SENP3 [77]. Importantly, key nucleolar proteins FBL, NPM1, and NOPP140 retain their mobility and evade retention, highlighting the specificity of this nucleolar sequestration [77]. The IGS IncRNA transcription correlates with the formation of detention centers [77]. The functional role of nucleolar sequestration is described for the VHL protein which degrades the hypoxia-inducible factor (HIF) in the presence of oxygen. Sequestration of VHL enables HIF to evade destruction and activate its target genes [89].

\section{Bynamic association of chromatin-with the nucleolus regulates nuclear processes.}

Aucleolus and the 3D genome organisation. One or several nucleoli present in the nucleus eccupy a large volume (up to 25\% of the nucleus), mostly in the central part of the nucleus; this volume is largely filled with transcribed rDNA and assembling ribosomes. In each cell, only a fraction of rRNA genes is transcriptionally active and localises within nucleoli. Inactive rDNA repeats are located at the periphery of the nucleolus contributing to the creation of perinucleolar inactive chromatin compartment $[7,90,91]$. Genomic segments located within this compartment are commonly referred to as nucleolius-associated chromatin domains (NADs) $[3,4]$. NADs centain sequences located in the p arms of acrocentric chromesomes, centromeric and pericentromeric chromatin of most chromosomes and subtelomeric regions of some chromosomes (Figure 3). Besides repetitive sequences, NADs contain more than 1000 structural genes including TCR genes, olfactory receptor, defensin genes as well as two families of immunoglobulin genes out of six. Many NAD-associated genes have similar features: they are tissue-specific and form large gene clusters [92]. NADs substantially overlap with laminaassociated domains (LADs) [93]. In each cell, only a portion of LADs identified in population studies is actually located close to nuclear lamina. After mitosis, LADs are stochastically reshuffled and LADs redistributed to the nuclear interior are frequently localised within the perinucleolar region [94]. In the interphase nucleus, each chromoseme forms a distinct ehromosomal territory probably linked to both nuclear lamina and the nucleolus as every 
ehromeseme contains both LADs and NADs. Furthermere, different chromosemal territeries interact with each other $[95,96]$. Being attached to the nucleolus, the nuclear lamina and to each өther, chromesemal territeries constitute a unified chromatin compartment that may be mechanically stretched and can sense mechanical stress [97]. In this scenario, the phaseseparated nuclear compartments, the largest of which is the nucleolus, play a role of globat chromatin organizers $[96,97]$. In particular, tethering of chromatin to nucleolus and nuclear speckles is likely to account for the spatial segregation of repressed and active chromatin eompartments revealed by $\mathrm{Hi} \mathrm{C}$ studies [98]. Chromoseme Conformation Capture (3C) and its genome-wide variant Hi-C provided a way to measure contact probabilities between ehromesomal segments. Hi-C analyses led to identification of the active and inactive ehromosemal compartments, self interacting topologically asseciating domains (TADs) and eontacts between chromesemes with an increasing reselution. Comparisen between TADs and NADs revealed that they were organized in a similar way, but NADs colocalized mostly with the inactive chromosemal compartments. The short range contacts occurred preferentially between sequences located within the same and neighbouring NADs, and the long-range contacts (over $>50 \mathrm{Mb}$ distance) occurred preferentially between sequences located outside NADs [99]. Interaction between the nucleolus and extra-nucleolar chromatin may stabilize weak interchromesemal contacts and serve as a centrefold for arrangement of chromøsemal territories inside the nucleus [100]. The association of specific genomic loci with the nucleolus may occur through their interaction with rDNA. Recent HiC experiments demonstrated that $5 \mathrm{~S}$ and $45 \mathrm{~S}$ arrays formed multiple contacts with genomic regions and genes on all chromosomes. Interestingly, no-direct physical interaction between the $5 \mathrm{~S}$ and $45 \mathrm{~S}$ rDNA repeats was observed [101].

Association with the nucleolus regulates genome functioning. NADs are globally enriched in heterochromatin marks, including $\mathrm{H} 3 \mathrm{~K} 27 \mathrm{me} 3, \mathrm{H} 3 \mathrm{~K} 9 \mathrm{me}$, and $\mathrm{H} 4 \mathrm{~K} 20 \mathrm{me} 3$. Gene targeting to the 
nucleolus and the perinucleolar region is correlated with reduced gene expression [102]. Localization of NADs in the peripheral region of the nucleolus may thus contribute to gene silencing [7]. Regulation of gene expression may involve changes in gene positioning or the pattern of their contacts with the nucleolus. Indeed, some processes are accompanied by relocalization of genomic loci vs. the nucleolus: centromeric and pericentromeric repeats are dissociated from the nucleolus in aging cells [99]. Association with the nucleolus globally correlates with the inactive transcriptional state of RNA polymerase II transcribed genes. Some exceptions exist: translocations of the CCNDI and MYC genes to the acrocentric chromosome 14 into the locus of the immunoglobulin heavy chain (IGH) genes lead to their relocalization towards the perinucleolar region and activation by the nucleolar protein NCL [6]. Association of the IGH genes with the nucleolus may also be necessary for recombination. Thus, B-cell maturation is accompanied by relocalization of the IGH locus in the prenucleolar region to a specific "recombination compartment" containing an activation-induced cytosine deaminase (AID). Somatic hypermutation and class switch recombination of immunoglobulin genes take place in these "recombination compartments" [8]. Localization of genes other than IGH within this compartment may significantly increase the probability of oncogenic translocations in Bcells [103]. Association of one allele of a monoallelically expressed gene with the nucleolus may participate in stochastic or imprinted allelic exclusion which could be the case of TCR, IGH and elfactory receptor genes $[104,105]$.

Nucleolar proteins, such as Ki-67, NCL and NPM1, mediate association of chromatin with the nucleolus. These proteins interact with CAF1, a chromatin assembly factor [99]. Depletion of the p150 CAF1 subunit led to a decreased association of certain genomic loci, including the $5 \mathrm{~S}$ fDNA, alpha satellite DNA, and the D4Z4 macrosatellite, with the nucleoli in human cells [106]. Depletion of the nucleoplasmin like protein NLP, a Drosophila homolog of NPM1, resulted in de-clustering of centromeres and a decrease in centromere association with the nucleolus-[107]. 
Normal fibroblasts and cancer cells depleted of NPM1 displayed deformed nucleoli and a

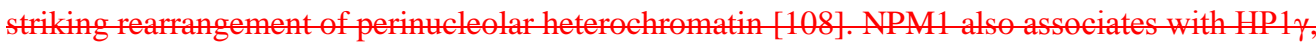
eore, linker histones and a centromere-specific histone variant CENP A [109]; NPM1 is required for efficient tethering of HP1 $\gamma$-enriched chromatin to the nucleolus. Thus, interaction with ehromatin and, in particular, heterochromatin proteins may be the major driver of chromatin anchoring to the nucleolus.

The nucleolus is also an essential platform for parental chromatin organization in murine oøcytes [110]. Enucleolated oocytes exhibit abnormal heterochromatin distribution. In the nucleolieontaining oøcytes, heterochromatin is anchored to the nucleoli and forms a ring like structure, whereas in enucleolated oøcytes, the heterochromatin forms chromocenter like foci. Oocytes deficient in the major protein of the nucleoplasmin family, NPM2, showed disorganization of perinucleolar chromatin, and expression of NPM2 alone sufficed to reconstitute the nucleolar structure in enucleolated embryos. Thus, NPM2 participates in anchoring and organization of chromatin in oocytes similarly to NPM1 in somatic cells.

CTCF, a structural protein that regulates 3D genome folding into TADs that often include coregulated and co-transcribed genes (reviewed in [111]), may also anchor/target specific loci to the perinucleolar space. CTCF interacts with NPM1 to tether insulators to the nucleolar periphery [112]. In Drosophila, CTCF interacts with NLP and the nucleolar protein Modulo to position centromeres in the perinucleolar region [107].

Non-coding RNAs participate in the chromatin tethering towards the nucleolar periphery. For example, Xist non-coding RNA (ncRNA) is responsible for the association of the inactive X ehromosome with the nucleolar periphery [113]. Xist loss after X inactivation leads to dissociation of X chromosome from the nucleolus. Interestingly, autosomes bearing 
translocations with the X chromosome also become preferentially associated with the nucleolus [114]. Firre ncRNA also participates in X inactivation. Firre is expressed from a perinucleolar locus located on the X chromosome; this locus contains CTCF and cohesin binding sites [115]. Firre transcription from the inactive X chromosome cooperates with CTCF binding to ensure perinucleolar positioning. Knockdown of Firre or its interaction partner hnRNPU interferes with the perinucleolar targeting of the inactive X chromosome. An imprinted antisense Kcnqlot nCRNA is transcribed only from the paternal allele and insures the allelic exclusion by targeting the paternal locus to the perinucleolar space where this $1 \mathrm{Mbp}$ region containing ten proteineoding genes is silenced $[116,117]$.

Although mTOR complex 1 (mTORC1) is predominantly cytosolic and localizes around the lysosomal membrane, several members of mTORC1, including mTOR itself, can also locate to the nucleus and the nucleolus [63-69]. Nuclear mTOR protein can bind to thousands of sites in the genome $[66,67]$ and interact with rDNA chromatin either directly [63-65] or via modulation of other rDNA-interacting factors [70,71]. Treatment with mTORC1 inhibitor rapamycin prevents mTOR localization to the nucleolus and interferes with the processing of ribosomal rRNAs [68]. One of the recent examples of the nucleolar activity of mTORC1 is related to the function of inhibitor of growth $1 \mathrm{~b}$ protein (ING1b), which associates with rDNA repeats and is required for the efficient recruitment of chromatin regulator HDAC1 to the nucleoli [69]. ING1 reduces mTOR localization to the nucleolus and promotes recruitment of HDAC1 to the nucleolar remodelling complex (NoRC) complex and to major Pol I transcription factor UBF1. $\underline{\text { Inversely, knockdown of ING1 results in the accumulation of mTOR in nucleolus and it }}$ association with UBF1.

Sequestration of proteins in the nucleus. Although most of the shuttling between the nucleolus and the nucleoplasm is reversible, recent studies indicate that the nucleolus can sequester and $\underline{\text { store various nuclear and cytoplasmic proteins including misfolded protein aggregates. These }}$ 
aggregates form proteinaceous particles that can promote proteotoxic stress and eventually cell death if they are not cleared by the ubiquitin-proteasome system. Protein aggregates may also form directly in the nucleoli when proteasome function is inhibited. [72]. These inclusions form

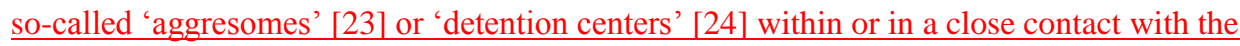
nucleoli (Figure 2); they are rich in protein and RNA [73]. Aggresome formation correlates with cell survival [74].

$\underline{\text { Various stresses lead not only to formation to misfolded proteins, but also to the expression of }}$ $\underline{\text { specific lncRNAs from the intergenic spacer separating individual rDNA transcription units (IGS }}$ $\underline{\text { lncRNAs) [75]. IGS lncRNA transcription correlates with the formation of nucleolar detention }}$ centers $[24]$ retaining DNA (cytosine-5)-methyltransferase 1 (DNMT1), the $\delta$ catalytic subunit of DNA polymerase (POLD1), Hsp70, RNF8, MDM2, APC2 [75], RPA16, RPA40, PES1, NOP52, $\underline{\text { RRP1B, NOM1, NOL1, SENP3, and von Hippel-Lindau (VHL) protein [24]. VHL protein }}$ degrades the hypoxia-inducible factor (HIF) in the presence of oxygen; sequestration of VHL enables HIF to evade destruction and activate its target genes [76]. Immobilization of these proteins inside the nucleolus is driven by specific nucleolar detention signals (NoDS) [75]. $\underline{\text { Importantly, key nucleolar proteins FBL, NPM1, and NOPP140 that do not contain these signals }}$ $\underline{\text { remain mobile and evade retention, highlighting the specificity of this nucleolar sequestration }}$ [24].

Dynamic association of chromatin with the nucleolus controls 3D genome organization.

Nucleolus and 3D genome organisation Nucleus may contain one or several nucleoli that occupy up to $25 \%$ of its volume. The nucleolus is largely filled with transcribed rDNA and assembling ribosomes. In each cell, only a fraction of rRNA genes is transcriptionally active and localise within nucleoli. Inactive rDNA repeats are located at the periphery of the nucleolus 
contributing to the creation of a perinucleolar inactive chromatin compartment $[5,77,78]$. The presence of heterochromatin at the nucleolar periphery is directly related to the positioning of silenced ribosomal genes in this area [79]. Silencing of rDNA repeats is mediated by NoRC that recruits histone-modifying and DNA methylating enzymes $[80,81]$. The NoRC recruited to the perinucleolar region may also introduce heterochromatic marks into other chromatin regions in the vicinity of the nucleolus. Interestingly, centromeric heterochromatin is frequently located close to nucleolus, and depletion of TIP5, a subunit of NoRC compromises both rDNA silencing and assembly of centromeric heterochromatin [82].

$\underline{\text { Genomic segments located within perinucleolar compartment are commonly referred to as }}$ nucleolus-associated chromatin domains (NADs) [83,84]. NADs contain sequences located in the short arms of acrocentric chromosomes, centromeric and pericentromeric chromatin of most chromosomes and subtelomeric regions of some chromosomes (Figure 3). Besides repetitive sequences, NADs contain more than 1000 genes including those encoding for the T-cell $\underline{\text { receptors, olfactory receptors and two families of immunoglobulin genes. Many NAD-associated }}$ genes have similar features: they are tissue-specific and form large gene clusters [85]. NADs substantially overlap with lamina-associated domains (LADs) [86]. Only a portion of LADs identified in population studies is located close to nuclear lamina. After mitosis, LADs are $\underline{\text { stochastically reshuffled, and LADs redistributed to the nuclear interior are frequently localised }}$ within the perinucleolar region [87].

What is the functional significance of NADs and how the nucleolus can regulate their functions? NADs are globally enriched in heterochromatin marks, including H3K27me3, H3K9me3, and H4K20me3. Gene targeting to the nucleolus and the perinucleolar region is globally correlated with reduced gene expression [88]. Localization of NADs in the peripheral region of the nucleolus may thus contribute to gene silencing [5]. Regulation of gene expression may involve 
changes in gene positioning or the pattern of their contacts with the nucleolus. Indeed, some processes are accompanied by relocalization of genomic loci vs. the nucleolus. For example, centromeric and pericentromeric repeats are dissociated from the nucleolus in aging cells [89]. Association with the nucleolus globally correlates with the inactive transcriptional state of RNA polymerase II-transcribed genes. Some exceptions exist: translocations of the CCNDI and MYC genes to the acrocentric chromosome 14 into the locus of the immunoglobulin heavy chain $\underline{(I G H)}$ genes lead to their relocalization towards the perinucleolar region and activation by NCL [4]. Association of the $I G H$ genes with the nucleolus may also be necessary for recombination. Thus, B-cell maturation is accompanied by relocalization of the IGH locus in the prenucleolar $\underline{\text { region to a specific "recombination compartment" containing an activation-induced cytidine }}$ deaminase (AID). Somatic hypermutation and class-switch recombination of immunoglobulin genes take place in these "recombination compartments" [6]. Localization of genes other than $\underline{I G H \text { within this compartment may significantly increase the probability of oncogenic }}$ translocations in B-cells [90]. Association of one allele of a monoallelically expressed gene with $\underline{\text { the nucleolus may participate in stochastic or imprinted allelic exclusion which could be the case }}$ for TCR, IGH and olfactory receptor genes [91,92].

In the interphase nucleus, each chromosome forms a distinct chromosomal territory that is likely linked to both the nuclear lamina and the nucleolus because every chromosome contains both LADs and NADs. Being attached to the nucleolus, the nuclear lamina and to each other [93,94], $\underline{\text { chromosomal territories constitute a unified chromatin compartment that is mechanically }}$ stretched [95] and can sense mechanical stress [96]. In this scenario, phase-separated nuclear compartments, the largest of which is the nucleolus, act as global chromatin organizers $[94,96]$. In particular, tethering of chromatin to the nucleolus and nuclear speckles is likely to account for $\underline{\text { the spatial segregation of repressed and active chromatin compartments [97]. These }}$ compartments likely corresponding to heterochromatin and euchromatin were identified by Hi-C 
[97]. Besides repressed and active chromatin compartments Hi-C and other recently developed $\underline{\text { experimental procedures allowed to identify self-interacting topologically associating domains }}$

(TADs) and contacts between chromosomes [94,97-99]. Interaction between the nucleolus and $\underline{\text { extra-nucleolar chromatin may stabilize weak interchromosomal contacts and serve as a }}$ centrefold for the arrangement of chromosomal territories inside the nucleus [100]. The association of specific genomic loci with the nucleolus may occur through their interaction with rDNA. Recent HiC experiments demonstrated that $5 \mathrm{~S}$ and $45 \mathrm{~S}$ gene arrays formed multiple contacts with genomic regions and genes on all chromosomes [101].

Association of chromatin with the nucleolus is mediated both by proteins and RNA. Nucleolar proteins Ki-67, NCL and NPM1 mediate the association of chromatin with the nucleolus. These proteins interact with CAF1, a chromatin assembly factor [89]. Depletion of the p150 CAF1

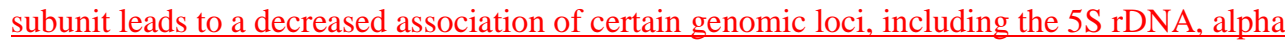
satellite DNA, and the D4Z4 macrosatellite, with nucleoli in human cells [102]. Depletion of NLP, a Drosophila homolog of NPM1, resulted in de-clustering of centromeres and a decrease in centromere association with the nucleolus [103]. Normal fibroblasts and cancer cells depleted of NPM1 displayed deformed nucleoli and a striking rearrangement of perinucleolar heterochromatin [104]. NPM1 also associates with HP1 $\gamma$, core linker histones and a centromerespecific histone variant CENP-A [105]; NPM1 is required for efficient tethering of HP1 $\gamma$ enriched chromatin to the nucleolus. Thus, interaction with chromatin and, in particular, heterochromatin proteins may be a major driver of chromatin anchoring to the nucleolus. CTCF, a structural protein that regulates 3D genome folding into TADs that often include co-regulated and co-transcribed genes (reviewed in [106,107]), may also anchor/target specific loci to the perinucleolar space. CTCF interacts with NPM1 to tether insulators to the nucleolar periphery [108]. In Drosophila, CTCF interacts with NLP and the nucleolar protein Modulo to position centromeres in the perinucleolar region [103]. 
Non-coding RNAs participate in the chromatin tethering towards the nucleolar periphery as well. For example, Xist and Firre non-coding RNAs (ncRNA) participate in X inactivation. Xist is responsible for the association of the inactive $\mathrm{X}$ chromosome with the nucleolar periphery [109]. $\underline{\text { Xist loss after } \mathrm{X} \text { inactivation leads to dissociation of } \mathrm{X} \text { chromosome from the nucleolus. }}$ Interestingly, autosomes bearing translocations with the X chromosome also become preferentially associated with the nucleolus [110]. Firre is expressed from a perinucleolar locus located on the X-chromosome; this locus contains $\mathrm{CTCF}$ and cohesin binding sites [111]. Firre transcription from the inactive $\mathrm{X}$ chromosome cooperates with CTCF binding to ensure perinucleolar positioning. Knockdown of Firre or its interaction partner hnRNPU interferes with the perinucleolar targeting of the inactive X chromosome. An imprinted antisense Kcnqlot ncRNA is transcribed only from the paternal allele and insures the allelic exclusion by targeting the paternal locus to the perinucleolar space where this $1 \mathrm{Mbp}$ region containing ten proteincoding genes is silenced $[112,113]$. Thus, nucleolus plays an important role in the 3D organization of the genome. It participates in organization of chromosome compartments and territories as well as heterochromatin assembly. This process involves several nucleolar proteins and non-coding RNAs.

\section{Concluding remarks}

Proteins can be sequestered into the nucleolus affecting their functions. At the same time, other proteins and RNA can be freely exchanged between the nucleolus and the nucleoplasm. This shuttling is impertant for many processes, including transcription regulation, telemere maintenance, DNA recombination and repair and apoptosis. Recent data also point to the emerging role of the nucleolus in organizing the genome folding and transcription by sequestering specific sequences to perinucleolar regions. Further studies will help us to decrypt the amazing complexity of this nuclear body. 
The key role of nucleolus as a regulatory hub is directly related to its main function, production of ribosomes. This process consumes more than a half of cell energy resources and thus should be coordinated with the actual needs of the cell in the ribosomes. Accordingly, many regulatory circuits link the production of ribosomes to the cell cycle progression which, in turn, can be blocked by stress responses. It is thus not surprising that nucleolus acquired a role of regulatory hub connecting many functional processes. The fundamental link between ribosome biogenesis and cell cycle progression is accomplished through involvement of certain proteins in cell cycle control and stress response on the one hand, and the regulation of ribosomal gene transcription and ribosome assembly on the other hand. Many of these proteins are sequestered within phaseseparated nucleoli but may shuttle to nucleoplasm in response to various stimuli.

The principal role of nucleolus in the 3D organization of the genome consists in creation of a nucleation center for the assembly of heterochromatin. This nucleation is due to silenced rRNA genes. Silencing of a portion of rRNA genes is an ancient phenomenon occurring even in lower eukaryotes. In multicellular organisms, the mechanism that silenced rRNA genes could be extended to other genes that are not used in various types of differentiated cells. Further studies will help us to decrypt the amazing complexity of the nucleols (see Outstanding questions).

\section{Acknowledgements}

We thank Dr. S.A. Golyshev for drawing the figures and many colleagues in the field for stimulating discussions; and apologize that we could not acknowledge all relevant work due to space constraints. This work was supported by grants from Plan Cancer (ENVIBURKITT), ANRS-and LNCC $\underline{A N R S}$ to YV, by the Russian Foundation for Basic Research (16-54-16014) and Russian Science Foundation (19-14-24-0002200016) to SVR, and by the Russian Science 
$\operatorname{Bex} 1$

\section{Membraneless nuclear compartments}

Eukaryotic cell nucleus contains a number of membraneless compartments such as nucleoli, Cajal bodies, PML bodies, nuclear speckles etc. [118]. These compartments are dynamic associates of proteins and nucleic acids and are slightly denser than the bulk of the nucleoplasm. Each type of membraneless compartments is connected to certain functional processes that are not necessarily related to each other [119]. Accordingly, most of the compartments contain a number of various proteins including many moonlighting proteins [120]. The proteins participating in assembly of nuclear compartments frequently possess intrinsically disordered demains [ 120 122]. These proteins/dømains may mediate weak affinity and non-specifie interactions with multiple target sites that trigger the liquid phase separation [123]. The phaseseparated droplets aceumulate macromolecules that possess an affinity to the components of the droplet interior. Usually a so called platform nucleates the assembly of liquid droplet nuclear eompartments. This may be either a protein (e.g. PML in case of PML bodies [124]) or a noncoding RNA (e.g. NEAT1 RNA in paraspeckles [125] or rRNA in nucleoli [126]). The nucleolus differs from other membraneless compartments in two ways. First, the nucleolus consists of at least three distinct phase-separated layers: droplets within droplets [127]. Second, the availability of pre rRNAs that constitutes a platform for nucleolus assembly directly depends on the ongoing rDNA transcription [128]. Suppression of rDNA transcription results in full or partial disruption of nucleoli and release into cytoplasm of a various proteins sequestered within nucleoli [128]. This is likely to be an important part of the cellular stress response mechanism [129]. 


\section{$\underline{B o x} 1$}

\section{$\underline{\text { Membraneless nuclear compartments }}$}

Eukaryotic cell nucleus contains a number of membraneless compartments such as nucleoli,

Cajal bodies, PML bodies, nuclear speckles etc. [114]. These compartments are dynamic associates of proteins and nucleic acids and are slightly denser than the bulk of the nucleoplasm. Each type of membraneless compartments is connected to certain functional processes that are not necessarily related to each other [115]. Accordingly, most of the compartments contain a number of various proteins including many moonlighting proteins [116]. The proteins participating in assembly of nuclear compartments frequently possess intrinsically disordered domains [116-118]. These proteins/domains may mediate weak-affinity and non-specific interactions with multiple target sites that trigger the liquid phase separation [119]. The phaseseparated droplets accumulate macromolecules that possess an affinity to the components of the droplet interior. Usually a so called platform nucleates the assembly of liquid droplet nuclear compartments. This may be either a protein (e.g. PML in case of PML-bodies [120]) or a noncoding RNA (e.g. NEAT1 RNA in paraspeckles [121] or rRNA in nucleoli [122]). The nucleolus differs from other membraneless compartments in two ways. First, the nucleolus consists of at least three distinct phase-separated layers: droplets within droplets [123]. Second, the availability of pre-rRNAs that constitutes a platform for nucleolus assembly directly depends on the ongoing rDNA transcription [124]. Suppression of rDNA transcription results in full or partial disruption of nucleoli and release into cytoplasm of a various proteins sequestered within nucleoli [124]. This is likely to be an important part of the cellular stress response mechanism [125]. 


\section{$\underline{\text { Figure Legends }}$}

Figure 1. DNA repair and telomere maintenance are regulated by protein shuttling between the nucleolus and the nucleoplasm.

Clockwise: APE1 interacts with nucleolar proteins NPM1 via its positively charged lysine residues. When some of these lysine residues are acetylated, NPM1 no longer interacts with APE1 and APE1 accumulates in nucleoplasm at the DNA damage sites. Nucleolar mTOR activates PolI transcription. The ING1/HDAC1 complex reduces nucleolar localization of mTOR and represses transeription. -WRN possesses a NoLS in its C-terminus; nucleolar localization of WRN is dependent on RNA Pol I transcription. When DNA repair is activated, WRN is dephosphorylated and moves from nucleolus to nucleoplasm. BLM can directly bind rDNA and interact with RNA Pol I. BLM switching between DNA repair and ribosome biogenesis occurs through protein-protein interactions and posttranslational modifications. TRAIP encodes a nucleolar protein that migrates to UV-induced DNA lesions in the nucleoplasm; inhibition of RNA Pol I activity also leads to TRAIP diffusion into the nucleoplasm. The telomerase complex biogenesis occurs in the nucleolus; TERT is retained in nucleoli through its interaction with NCL. Activity of TRF1 is modulated by interaction with GNL3L that stabilizes TRF1 while NSM promotes its degradation, inhibits TRF1 dimerization and shortens its dynamic association with the telomere.Nucleolar localization of TRF2 is promoted by the nucleolar protein NOLC1. TRF2 also binds rDNA and promotes rRNA transcription. NCL forms nucleoplasmic foci at sites of DSB repair where it is implicated in chromatin remodelling while the mail pool of NCL is located in the nucleolus. Ionizing radiation, cisplatin or etoposide treatment leads to NPM1 phosphorylation and its relocalization from the nucleolus to the DSB foci in the nucleoplasm.

Figure 2. Sequestration of nuclear and cytoplasmic proteins in the nucleolus.

Misfolded proteins aggregate and form proteinaceous particles that are transported into the nucleolus form so-called 'aggresomes' or 'detention centers'. p21Cip1 transits through the 
nucleolus on its way from the nucleus to the cytoplasm. DNA damage inhibits this transit and induces formation of p21Cip1-containing intranucleolar bodies (INoBs) containing SUMO-1, UBC9, Cdk2, Cyclin E, PCNA, p53 and MDM2. Transcriptional, acidic or heat stress leads to expression of lncRNAs from the rDNA intergenic spacer. These transcripts capture and immobilize inside nucleoli several important proteins, including VHL, DNMT1, tPOLD1, Hsp70, RNF8, MDM2, APC2, RPA16 and RPA40, PES1, NOP52, RRP1B, NOM1, NOL1, and SENP3. Key nucleolar proteins FBL, NPM1, and NOPP140 retain their mobility and evade immobilization, highlighting the specificity of this nucleolar sequestration.

Figure 3. Dynamic association of chromatin with the nucleolus regulates nuclear processes Clockwise: nucleoli-associated chromatin domains (NADs) represent hundreds of extended genomic loci comprising $4 \%$ of the human genome. NADs contain sequences located in the parms of acrocentric chromosomes, centromeric and pericentromeric chromatin of most chromosomes and subtelomeric regions of some chromosomes. Association with the nucleolus globally correlates with the inactive transcriptional state of RNA polymerase II-transcribed genes, with some exceptions. Association with the nucleolus may also participate in allelic exclusion. Somatic hypermutation and class-switch recombination occur in the specific "recombination compartment" located in the prenucleolar region and containing AID. Inactive X chromosome is associated with the nucleolar periphery; this association is due to Xist and Firre non-coding RNAs. 


\section{References}

1 Hernandez-Verdun, D. et al. (2010) The nucleolus: structure/function relationship in RNA metabolism. Wiley Interdiscip. Rev. RNA 1, 415-431

2 Andersen, J.S. et al. (2005) Nucleolar proteome dynamics. Nature 433, 77-83

3 Németh, A. et al. (2010) Initial genomies of the human nucleolus. PLos Genet. 6, e1000889

43 $=$ van Koningsbruggen, S.et al. (2010) High-Resolution Whole-Geneme Sequeneing Reveals That Specific Chromatin Domains frem Most Human Chromesomes Associate with Nuleli. Mol. Biol. Cell 21,3735-3748

$5 \quad$ Padeken, J. and Heun, P. (2014) Nucleolus and nuclear periphery: Velcro for heterochromatin. Curr. Opin. Cell Biol. 28, 54-60

64 Allinne, J. et al. (2014) Perinucleolar relocalization and nucleolin as crucial events in the transcriptional activation of key genes in mantle cell lymphoma. Blood 123, 2044-53

75 Matheson, T.D. and Kaufman, P.D. (2016) Grabbing the genome by the NADs. Chromosoma $125,361-71$

8 f Pichugin, A. et al. (2017) The IGH locus relocalizes to a "recombination compartment" in the perinucleolar region of differentiating B-lymphocytes. Oncotarget 8 ,

97 Scott, D.D. and Oeffinger, M. (2016) Nucleolin and nucleophosmin: nucleolar proteins with multiple functions in DNA repair. Biochem. Cell Biol. 94, 419-432

$10 \underline{8}$ Ogawa, L.M. and Baserga, S.J. (2017) Crosstalk between the nucleolus and the DNA damage response. Mol. Biosyst. 13, 443-455

119 Boulon, S. et al. (2010) The nucleolus under stress. Mol. Cell 40, 216-27

1210 Carmo-Fonseca, M. et al. (2000) To be or not to be in the nucleolus. Nat Cell Biol 2, E107-12

1311 Emmott, E. and Hiscox, J.A. (2009) Nucleolar targeting: the hub of the matter. EMBO Rep. 10, 231-8 
1412 Musinova, Y.R. et al. (2015) A charge-dependent mechanism is responsible for the

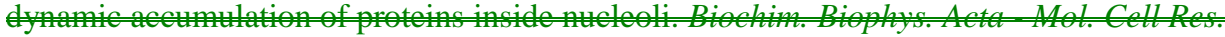

$1853,101-110$

15 Musinova, Y.R. et al. (2011) Nucleolar localization/retention signal is responsible for transient accumulation of histone $\mathrm{H} 2 \mathrm{~B}$ in the nucleolus through electrostatic interactions. Biochim. Biophys. Acta - Mol. Cell Res. 1813, 27-38

13 Savada, R.P. and Bonham-Smith, P.C. (2013) Charge versus sequence for nuclear/nucleolar localization of plant ribosomal proteins. Plant Mol. Biol. 81, 477-93

16 Savala, R.P. and Bonham-Smith, P.C.(2013) Chargersus for nelelear/nueleolar loealization of plant ribosomal proteins. Plant Mol. Biol.81,477-93

$17 \underline{14}$ Martin, R.M. et al. (2015) Principles of protein targeting to the nucleolus. Nucleus 6, 314 25

15 Musinova, Y.R. et al. (2015) A charge-dependent mechanism is responsible for the dynamic accumulation of proteins inside nucleoli. Biochim. Biophys. Acta-Mol. Cell Res. $\underline{\underline{1853,101-110}}$

1816 Visvanathan, A. et al. (2013) Modulation of Higher Order Chromatin Conformation in Mammalian Cell Nuclei Can Be Mediated by Polyamines and Divalent Cations. PLoS One 8, e67689

1917 Maeshima, K. et al. (2018) A Transient Rise in Free Mg 2+ Ions Released from ATP-Mg Hydrolysis Contributes to Mitotic Chromosome Condensation. Curr. Biol. 28, 444-451.e6

$20 \underline{18}$ Sen Gupta, A. et al. (2018) Nucleolin modulates compartmentalization and dynamics of histone 2B-ECFP in the nucleolus. Nucleus DOI: 10.1080/19491034.2018.1471936

$21 \underline{19}$ Lessard, F. et al. (2010) The ARF Tumor Suppressor Controls Ribosome Biogenesis by Regulating the RNA Polymerase I Transcription Factor TTF-I. Mol. Cell 38, 539-550

2220 Misteli, T. (2001) Protein dynamics: implications for nuclear architecture and gene expression. Science 291, 843-7 
2321 Dundr, M. and Misteli, T. (2001) Functional architecture in the cell nucleus. Biochem. J. $356,297-310$

2422 Handwerger, K.E. et al. (2005) Cajal Bodies, Nucleoli, and Speckles in the Xenopus Oocyte Nucleus Have a Low-Density, Sponge-like Structure. Mol. Biol. Cell 16, 202-211

23 Komarova, T. V et al. (2012) Rapid and massive green fluorescent protein production leads to formation of protein Y-bodies in plant cells. Biochemistry. (Mosc). 77, 603-8

24 Jacob, M.D. et al. (2013) Environmental cues induce a long noncoding RNA-dependent remodeling of the nucleolus. Mol. Biol. Cell 24, 2943-2953

25 Lirussi, L. et al. (2012) Nucleolar accumulation of APE1 depends on charged lysine residues that undergo acetylation upon genotoxic stress and modulate its BER activity in cells. Mol. Biol. Cell 23, 4079-96

26 Vascotto, C. et al. (2009) APE1/Ref-1 Interacts with NPM1 within Nucleoli and Plays a Role in the rRNA Quality Control Process. Mol. Cell. Biol. 29, 1834-1854

2527 Chen, L. et al. (2003) WRN, the protein deficient in Werner syndrome, plays a critical structural role in optimizing DNA repair. Aging Cell 2, 191-199

28 Shiratori, M. ed. (2002) WRN heliease acelerates the transeription of ribosomal RNA a 21,244754

26 Moore, H.M. et al. (2011) Quantitative Proteomics and Dynamic Imaging of the Nucleolus Reveal Distinct Responses to UV and Ionizing Radiation. Mol. Cell. Proteomics 10, M111.009241

27 Grabarz, A. et al. (2013) A role for BLM in double-strand break repair pathway choice: prevention of CtIP/Mre11-mediated alternative nonhomologous end-joining. Cell Rep. 5, $21-8$

29 Brosh, R.M. (2013) DNA helicases involved in DNA repair and their roles in cancer. Nat. Rev. Cancer 13, 542-558

30 Blander, G. et al. (2002) DNA damage-induced translocation of the Werner helicase is 
regulated by acetylation. J. Biol. Chem. 277, 50934-40

31_ Tikoo, S. et al. (2013) Ubiquitin-dependent recruitment of the Bloom Syndrome helicase upon replication stress is required to suppress homologous recombination. EMBO J. 32 ,

\section{$\underline{1778-1792}$}

32 Shiratori, M. et al. (2002) WRN helicase accelerates the transcription of ribosomal RNA as a component of an RNA polymerase I-associated complex. Oncogene $21,2447-54$

28_Lirussi, L.etal. (2012) Nueleolar aceumulation-of APE1 depends on charged 1ysine residues that undergo acetylation upon genotoxic stress and modulate its BER activity in eells. Mol. Biol. Cell 23,4079-96

29 Chen, L.e al. (2003) WRN, the protein defieient in Werner syndrome, plays a ritieal

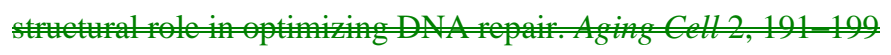

30 Brosh, R.M. (2013) DNA helieases inved in DNA repair and their roles in eancer. Nat. Rev. Cancer 13,542558

31 Blander, G. et al. (2002) DNA damage-induced transloeation of the Werner heliease is by 277,5093440

3233 Tangeman, L. et al. (2016) Regulation of BLM Nucleolar Localization. Genes (Basel). 7, 69

3334 Grierson, P.M. et al. (2012) BLM helicase facilitates RNA polymerase I-mediated ribosomal RNA transcription. Hum. Mol. Genet. 21, 1172-83

$34 \underline{35}$ Grierson, P.M. et al. (2013) Collaborating functions of BLM and DNA topoisomerase I in regulating human rDNA transcription. Mutat. Res. 743-744, 89-96

35 Tikeo, S. et al. (2013) Ubiquitin-dependent recruitment of the Bloom Syndrome helicase upon replication stress is required to suppres homologeus recombination. EMBO J.32, $1778-1792$

36 Larsen, D.H. et al. (2014) The NBS1-Treacle complex controls ribosomal RNA transcription in response to DNA damage. Nat. Cell Biol. 16, 792-803 
37 Harley, M.E. et al. (2016) TRAIP promotes DNA damage response during genome replication and is mutated in primordial dwarfism. Nat. Genet. 48, 36-43

38 Chen, Y. et al. (2018) Nucleolar residence of the seckel syndrome protein TRAIP is coupled to ribosomal DNA transcription. Nucleic Acids Res. DOI: 10.1093/nar/gky775

3937 Chen, D. and Huang, S. (2001) Nucleolar components involved in ribosome biogenesis cycle between the nucleolus and nucleoplasm in interphase cells. J. Cell Biol. 153, 169-76

38 Indig, F.E. et al. (2012) Nucleolin inhibits G4 oligonucleotide unwinding by Werner helicase. PLoS One 7, e35229

4039 Kobayashi, J. et al. (2012) Nucleolin participates in DNA double-strand break-induced damage response through MDC1-dependent pathway. PLoS One 7, e49245

$41 \underline{40}$ Goldstein, M. et al. (2013) Nucleolin mediates nucleosome disruption critical for DNA double-strand break repair. Proc. Natl. Acad. Sci. 110, 16874-16879

42 Szebeni, A. and Olsøn, M.O.J. (2008) Nucleolar protein B23 has molecular chaperone activities. Protein Sei. 8, 905912

43 Okuwaki, M. et al. (2001) Function of nucleophosmin/B23, a nucleolar acidic protein, as a histone chaperone. FEBS Lett. 506,2726

$44 \underline{1}$ Angelov, D. et al. (2006) Nucleolin is a histone chaperone with FACT-like activity and assists remodeling of nucleosomes. EMBO J. 25, 1669-1679

$45 \underline{42}$ Poletto, M. et al. (2014) Nucleophosmin modulates stability, activity, and nucleolar accumulation of base excision repair proteins. Mol. Biol. Cell 25, 1641-52

$46 \underline{43}$ Koike, A. et al. (2010) Recruitment of phosphorylated NPM1 to sites of DNA damage through RNF8-dependent ubiquitin conjugates. Cancer Res. 70, 6746-56

4744 Fu, D. and Collins, K. (2007) Purification of Human Telomerase Complexes Identifies Factors Involved in Telomerase Biogenesis and Telomere Length Regulation. Mol. Cell $\underline{28,773-785}$

45 Angrisani, A. et al. (2014) Human dyskerin: beyond telomeres. Biol. Chem. 395, 593-610 
46 Chen, D. and Huang, S. (2001) Nucleolar components involved in ribosome biogenesis

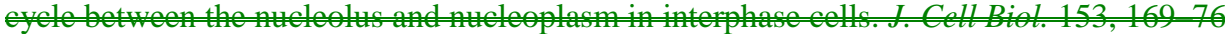

48 Colombe, E. et al. (2011) Nucleophosmin and its complex network: a possible therapeutic target in hematological diseases. Oncogene 30, 2595-609

49 Tajrishi, M.M. et al. (2011) Nucleolin. Commun. Integr. Biol. 4, $267-275$

50 Lee, J.H. et al. (2014) Catalytically active telomerase holoenzyme is assembled in the dense fibrillar component of the nucleolus during S phase. Histochem. Cell Biol. 141, $137-152$

5147 Wong, J.M.Y. et al. (2002) Subnuclear shuttling of human telomerase induced by transformation and DNA damage. Nat. Cell Biol. 4, 731-6

48 Yang, Y. et al. (2002) Nucleolar localization of hTERT protein is associated with telomerase function. Exp. Cell Res. 277, 201-9

5249 Etheridge, K.T. et al. (2002) The Nucleolar Localization Domain of the Catalytic Subunit of Human Telomerase. J. Biol. Chem. 277, 24764-24770

$53 \underline{50}$ Lin, J. et al. (2008) Nucleolar localization of TERT is unrelated to telomerase function in human cells. J. Cell Sci. 121, 2169-2176

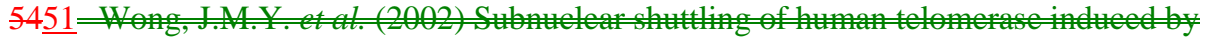

transformation and DNA damage. Nat. Cell Biol. 4,731-6

55 Gonzalez, O.G. et al. (2014) Telomerase stimulates ribosomal DNA transcription under hyperproliferative conditions. Nat. Commun. 5, 4599

5652 Zhangr, S. et. (2004) Nucleolar loealization of the human telomerie repeat binding factor Z(TRF2).J.Gell Sei. $117,3935-3945$

57 Yuan, F. et al. (2017) Nucleolar and coiled-body phosphoprotein 1 (NOLC1) regulates the nucleolar retention of TRF2. Cell death Discov. 3, 17043

5853 Zhang, S. et al. (2004) Nucleolar localization of the human telomeric repeat binding factor 2(TRF2). J. Cell Sci. 117, 3935-3945 
54 Yuan, F. et al. (2018) Nucleolar TRF2 attenuated nucleolus stress-induced HCC cell-cycle arrest by altering rRNA synthesis. Cell Death Dis. 9, 518

55 Phair, R.D. and Misteli, T. (2000) High mobility of proteins in the mammalian cell nucleus. Nature 404, 604-9

$\underline{56}$ Dundr, M. et al. (2000) The dynamics of postmitotic reassembly of the nucleolus. J. Cell Biol. 150, 433-46

57 Abella, N. et al. (2010) Nucleolar Disruption Ensures Nuclear Accumulation of p21 upon DNA Damage. Traffic 11, 743-755

58 Brun, S. et al. (2017) SUMO regulates p21Cip1 intracellular distribution and with p21Cip1 facilitates multiprotein complex formation in the nucleolus upon DNA damage. $\underline{\underline{P L O S} \text { One 12, e0178925 }}$

59 Zhu, Q. et al. (2009) GNL3L stabilizes the TRF1 complex and promotes mitotic transition. J. Cell Biol. 185, 827-839

60 Zhu, Q. et al. (2006) Nucleostemin Delays Cellular Senescence and Negatively Regulates TRF1 Protein Stability. Mol. Cell. Biol. 26, 9279-9290

59 Saxena, A. et al. (2006) Nucleolin inhibits Hdm2 by multiple pathways leading to p53 stabilization. Oncogene 25, 7274-7288

60 Kurki, S. et al. (2004) Nucleolar protein NPM interacts with HDM2 and protects tumor suppressor protein p53 from HDM2-mediated degradation. Cancer Cell 5, 465-75

61 Meng, L. et al. (2011) Nucleostemin inhibits TRF1 dimerization and shortens its dynamic association with the telomere.(2008) Nucleoplasmic mobilization of nucleostemin stabilizes MDM2 and promotes G2-M progression and cell survival. J. Cell Sci. 124, $3706-3714 \underline{121,4037-4046}$

62 Ma, Y. et al. (2018) mTORC1 pathway in DNA damage response. Biochim. Biophys. Acta - Mol. Cell Res. 1865, 1293-1311

63 Li, H. et al. (2006) Nutrient regulates Tor1 nuclear localization and association with 
rDNA promoter. Nature 442, 1058-1061

64 Tsang, C.K. et al. (2003) Chromatin-mediated regulation of nucleolar structure and RNA Pol I localization by TOR. EMBO J. 22, 6045-6056

65 Tsang, C.K. et al. (2010) mTOR binds to the promoters of RNA polymerase I- and IIItranscribed genes. Cell Cycle 9, 953-7

66 Audet-Walsh, É. et al. (2017) Nuclear mTOR acts as a transcriptional integrator of the androgen signaling pathway in prostate cancer. Genes Dev. 31, 1228-1242

67 Chaveroux, C. et al. (2013) Molecular and Genetic Crosstalks between mTOR and ERRo Are Key Determinants of Rapamycin-Induced Nonalcoholic Fatty Liver. Cell Metab. 17, 586-598

68 Iadevaia, V. et al. (2012) mTOR signaling regulates the processing of pre-rRNA in human cells. Nucleic Acids Res. 40, 2527-2539

69 Rajarajacholan, U.K. et al. (2017) ING1 regulates rRNA levels by altering nucleolar chromatin structure and mTOR localization. Nucleic Acids Res. 45, 1776-1792

70 Holz, M.K. et al. (2005) mTOR and S6K1 mediate assembly of the translation preinitiation complex through dynamic protein interchange and ordered phosphorylation events. Cell 123, 569-80

$71 \underline{70}$ Grove, A. (2018) Control of RNA polymerase II-transcribed genes by direct binding of TOR kinase. Curr. Genet. 64, 131-135

7271 Panday, A. et al. (2017) DNA damage regulates direct association of TOR kinase with the RNA polymerase II-transcribed HMO1 gene. Mol. Biol. Cell 28, 2449-2459

73 Malatesta, M. et al. (1994) Cytochemical and immunocytochemical characterization of nuclear bodies during hibernation. Eur. J. Cell Biol. 65, 82-93

74 Ochs, R.L. et al. (1994) Coiled bodies in the nucleolus of breast cancer cells. J. Cell Sci. 107 (Pt 2), 38599

75 Trinkle Muleahy, L. and Sleeman, J.E. (2017) The Cajal body and the nucleolus: 
\&quot;In a relationship\&quot; or \&quot;It's complicated\&quot;? RNA Biol. 14, 739 751

7672 Latonen, L. et al. (2011) Proteasome inhibitors induce nucleolar aggregation of proteasome target proteins and polyadenylated RNA by altering ubiquitin availability. Oncogene 30, 790-805

73 Komarova, T. V etal. (2012) Rapid and massive green fluoresent protein production 1.

77 Jacob, M.D.etal. (2013) Envirenmental cues induce a long noncoding RNA dependent remoling of the nueleolus. Mol. Biol. Cell 24, 2943-2953

78 Goggin, K. et al. (2008) Prion protein aggresomes are poly(A)+ ribonucleoprotein complexes that induce a PKR-mediated deficient cell stress response. Biochim. Biophys. Acta - Mol. Cell Res. 1783, 479-491

7974 Kawaguchi, Y. et al. (2003) The deacetylase HDAC6 regulates aggresome formation and cell viability in response to misfolded protein stress. Cell $115,727-38$

75 Audas, T.E. et al. (2012) Immobilization of proteins in the nucleolus by ribosomal intergenic spacer noncoding RNA. Mol. Cell 45, 147-57

76 Mekhail, K. et al. (2004) HIF activation by pH-dependent nucleolar sequestration of VHL. Nat. Cell Biol. 6, 642-647

77 Pontvianne, F. et al. (2013) Subnuclear partitioning of rRNA genes between the nucleolus and nucleoplasm reflects alternative epiallelic states. Genes Dev. 27, 1545-1550

78 Jakociunas, T. et al. (2013) Subnuclear relocalization and silencing of a chromosomal region by an ectopic ribosomal DNA repeat. Proc. Natl. Acad. Sci. 110, E4465-E4473

79 Zhou, Y. et al. (2002) The chromatin remodeling complex NoRC targets HDAC1 to the $\underline{\text { ribosomal gene promoter and represses RNA polymerase I transcription. EMBO J. } 21,}$ $\underline{4632-40}$

$\underline{80}$ Santoro, R. and Grummt, I. (2005) Epigenetic mechanism of rRNA gene silencing: temporal order of NoRC-mediated histone modification, chromatin remodeling, and DNA 
methylation. Mol. Cell. Biol. 25, 2539-46

81 Santoro, R. et al. (2002) The nucleolar remodeling complex NoRC mediates

heterochromatin formation and silencing of ribosomal gene transcription. Nat. Genet. 32, $\underline{393-396}$

82 Guetg, C. et al. (2010) The NoRC complex mediates the heterochromatin formation and $\underline{\text { stability of silent rRNA genes and centromeric repeats. EMBO J. 29, 2135-46 }}$

83 van Koningsbruggen, S. et al. (2010) High-Resolution Whole-Genome Sequencing Reveals That Specific Chromatin Domains from Most Human Chromosomes Associate with Nucleoli. Mol. Biol. Cell 21, 3735-3748

84 Németh, A. et al. (2010) Initial genomics of the human nucleolus. PLoS Genet. 6, $\underline{\mathrm{e} 1000889}$

85 Latenen, L.etal. (2011) Proteasome inhibitors induce nucleolar agraregation of proteme taret proteins and polyalenylated RNA by altering ubiquitin avallability. 30,790-805

80 Abella, N. al. (2010) Nuleolar Dismution Enowes Nuclear Acemulation of 21 upen DNA Damage. Traffic 11,743-755

81 Brun, S. al. (2017) SUMO rolates 21Cip1 in p21Cip1 facilitates multiprotein complex formation in the nucleolus upen DNA damage. 12,178925

82 Kieffer Kwon, P. et al. (2004) Cell-specific Nucleolar Localization of TBP related Factor 2. Mol. Biol. Cell 15, 4356-4368

83 Youn, H. et al. (2018) RaRF confers RA resistance by sequestering RAR to the nucleolus and regulating MCL1 in leukemia cells. Oncogene 37, 352-362

84 Grummt, I. (2013) The nucleolus guardian of cellular homeostasis and genome integrity. Chromesema 122, 48797

85 Németh, A. and Grummt, I. (2018) Dynamic regulation of nucleolar architecture. Curr. 
Opin. Cell Biol. 52, 105-114

86 Phair, R.P. and Misteli, T. (2000) High mobility of proins in the mammalian

muleus. Nature 404,604-9

87 Dundr, M.et. (2000) The dynamies of postmitotic reasembly the nueledus. J.Cell

Biol. $150,433-46$

88 Autas, T.E. (2012) Immobilizan of proin in the nutur by ribosmat interenic spacer nonding RNA. Mol. Cell 45, 147,57

89. Mekhail, K.e al. (2004) HIF activation by pH-dependent nucleolar sequestration of VHIL. Nat. Cell Biol. 6, 642-647

90 Pontvianne, F. el al. (2013) Subnuclear pantitioning of rRNA genes between the nucleolus a $27,1545 \quad 1550$

91 Jakeciunas, T. et al. (2013) Subnuclear reloealization and sileneing of a chromesomal region by an topic ribosomal DNA repeat. Proc. Natl. Acad. Sei. 110, E4465-E4473

92 Padeken, J. and Heun, P. (2014) Nucleolus and nuclear periphery: velcro for heterochromatin. Curr. Opin. Cell Biol. 28, 54-60

$93 \underline{86}$ Guelen, L. et al. (2008) Domain organization of human chromosomes revealed by mapping of nuclear lamina interactions. Nature 453, 948-951

$94 \underline{87}$ Kind, J. et al. (2013) Single-cell dynamics of genome-nuclear lamina interactions. Cell $153,178-192$

95 $\underline{88}$ Fedoriw, A.M. et al. (2012) Nucleolar Association and Transcriptional Inhibition through 5S rDNA in Mammals. PLoS Genet. 8, e1002468

89 Dillinger, S. et al. (2017) Nucleolus association of chromosomal domains is largely maintained in cellular senescence despite massive nuclear reorganisation. PLoS One 12, $\underline{\underline{\mathrm{e} 0178821}}$

90 Sklyar, I. et al. (2016) Distinct Patterns of Colocalization of the CCND1 and CMYC Genes With Their Potential Translocation Partner IGH at Successive Stages of B-Cell 
Differentiation. J. Cell. Biochem. 117, 1506-1510

91 Rada, C. and Ferguson-Smith, A.C. (2002) Epigenetics: monoallelic expression in the immune system. Curr. Biol. 12, R108-10

92 Monahan, K. and Lomvardas, S. (2015) Monoallelic expression of olfactory receptors. Annu. Rev. Cell Dev. Biol. 31, 721-40

93 Kalhor, R. et al. (2011) Genome architectures revealed by tethered chromosome conformation capture and population-based modeling. Nat. Biotechnol. 30, 90-8

9694 Quinodoz, S.A. et al. (2018) Higher-Order Inter-chromosomal Hubs Shape 3D Genome Organization in the Nucleus. Cell 174, 744-757.e24

9795 Ulianov, S. V et al. (2019) Nuclear lamina integrity is required for proper spatial organization of chromatin in Drosophila. Nat. Commun. 10, 1176

96 Shin, Y. et al. (2018) Liquid Nuclear Condensates Mechanically Sense and Restructure the Genome. Cell 175, 1481-1491.e13

9897 Lieberman-Aiden, E. et al. (2009) Comprehensive mapping of long-range interactions reveals folding principles of the human genome. Science (80-. ). 326, 289-293

9998 Rao, S.S.P. et al. (2014) A 3D map of the human genome at kilobase resolution reveals principles of chromatin looping. Cell 159, 1665-80

99 Beagrie, R.A. et al. (2017) Complex multi-enhancer contacts captured by genome architecture mapping. Nature 543, 519-524

Dillinger, S. et al. (2017) Nucleolus asociation of chromesomal domains is largely main in 00178821

100 Pontvianne, F. et al. (2016) Identification of Nucleolus-Associated Chromatin Domains Reveals a Role for the Nucleolus in 3D Organization of the A. thaliana Genome. Cell Rep. $16,1574-1587$

101 Yu, S. and Lemos, B. (2016) A Portrait of Ribosomal DNA Contacts with Hi-C Reveals 
5S and 45S rDNA Anchoring Points in the Folded Human Genome. Genome Biol. Evol. 8, 3545-3558

102102 Fedoriw, A.M. et al. (2012) Nueleolar Association and Transeriptional Inhibition

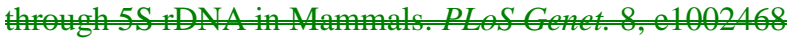

103 Sklyar, I.etal. (2016) Distinet Patterns of Colocalization of the CCND1 and CMYC

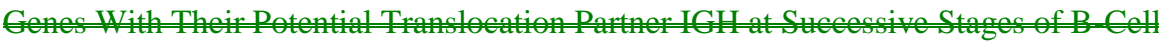

Differentiation.J.Cell. Biochem.117, 1506-1510

104 Rala, C. and Ferguson-Smith, A.C. $(2002)$ Epigeneties: monorllelie expression in the

immunesystem. Eufr. Biol. $12, \mathrm{R} 108-10$

105 -Monahan, K. and Lomvarelas, S. (2015) Menoallelie expression of olfactory reeptors.

An. R. CWD. B. 31,721-40

106 Smith, C.L. et al. (2014) A separable domain of the p150 subunit of human chromatin assembly factor-1 promotes protein and chromosome associations with nucleoli. Mol.

Biol. Cell 25, 2866-81

$107 \underline{103} \quad$ Padeken, J. et al. (2013) The nucleoplasmin homolog NLP mediates centromere clustering and anchoring to the nucleolus. Mol. Cell 50, 236-49

108104 Holmberg Olausson, K. et al. (2014) Loss of Nucleolar Histone Chaperone NPM1

Triggers Rearrangement of Heterochromatin and Synergizes with a Deficiency in DNA

Methyltransferase DNMT3A to Drive Ribosomal DNA Transcription. J. Biol. Chem. 289, $34601-34619$

$109 \underline{105} \quad$ Foltz, D.R. et al. (2006) The human CENP-A centromeric nucleosome-associated complex. Nat. Cell Biol. 8, 458-69

110 Ogushi, S. et al. (2017) Reconstitution of the oөcyte nucleolus in mice through a single mucleolar protein, NPM2. J. Cell Sei. 130, 2416-2429

$114 \underline{106}$ Eagen, K.P. (2018) Principles of Chromosome Architecture Revealed by Hi-C.

Trends Biochem. Sci. 43, 469-478 
112107 Razin, S. V and Ulianov, S. V (2017) Gene functioning and storage within a

\section{folded genome. Cell. Mol. Biol. Lett. 22, 18}

108 Yusufzai, T.M. et al. (2004) CTCF Tethers an Insulator to Subnuclear Sites, Suggesting

Shared Insulator Mechanisms across Species. Mol. Cell 13, 291-298

113109 Zhang, L.-F. et al. (2007) Perinucleolar Targeting of the Inactive X during S

Phase: Evidence for a Role in the Maintenance of Silencing. Cell 129, 693-706

114110 Zhang, Y. et al. (2012) Spatial organization of the mouse genome and its role in recurrent chromosomal translocations. Cell 148, 908-21

115111 Yang, F. et al. (2015) The lncRNA Firre anchors the inactive X chromosome to the nucleolus by binding CTCF and maintains H3K27me3 methylation. Genome Biol. 16, 52

116112 Mohammad, F. et al. (2008) Kcnq1ot1/Lit1 noncoding RNA mediates transcriptional silencing by targeting to the perinucleolar region. Mol. Cell. Biol. 28, 3713-28

$117 \underline{113}$ Kanduri, C. (2011) Kenq1ot1: a chromatin regulatory RNA. Semin. Cell Dev. Biol. 22, 343-50

118114 Mao, Y.S. et al. (2011) Biogenesis and function of nuclear bodies. Trends Genet. $27,295-306$

119115 Ulianov, S. V et al. (2015) Nuclear compartments, genome folding, and enhancerpromoter communication. Int. Rev. Cell Mol. Biol. 315, 183-244

120116 Meng, F. et al. (2015) Compartmentalization and Functionality of Nuclear

Disorder: Intrinsic Disorder and Protein-Protein Interactions in Intra-Nuclear

Compartments. Int. J. Mol. Sci. 17, 24

121117 Sawyer, I.A. et al. (2018) Membraneless nuclear organelles and the search for phases within phases. Wiley Interdiscip. Rev. RNA DOI: 10.1002/wrna.1514

122118 Darling, A.L. et al. (2018) Intrinsically Disordered Proteome of Human 
Membrane-Less Organelles. Proteomics 18, e1700193

123119 Uversky, V.N. (2017) Protein intrinsic disorder-based liquid-liquid phase transitions in biological systems: Complex coacervates and membrane-less organelles.

Adv. Colloid Interface Sci. 239, 97-114

$124 \underline{120}$ Ishov, A.M. et al. (1999) PML is critical for ND10 formation and recruits the PML-interacting protein daxx to this nuclear structure when modified by SUMO-1. J. Cell Biol. 147, 221-34

125121 Bond, C.S. and Fox, A.H. (2009) Paraspeckles: nuclear bodies built on long noncoding RNA. J. Cell Biol. 186, 637-44

126122 Falahati, H. et al. (2016) Nucleation by rRNA Dictates the Precision of Nucleolus Assembly. Curr. Biol. 26, 277-85

$127 \underline{123}$ Feric, M. et al. (2016) Coexisting Liquid Phases Underlie Nucleolar Subcompartments. Cell 165, 1686-97

128124 Brégnard, C. et al. (2014) DNA damage repair machinery and HIV escape from innate immune sensing. Front. Microbiol. 5, 176

129125 Mayer, C. and Grummt, I. (2005) Cellular stress and nucleolar function. Cell Cycle 4, 1036-8 